\title{
Numerical Simulation of Rock Cutting with a Diamond Sawblade Based on LS-DYNA
}

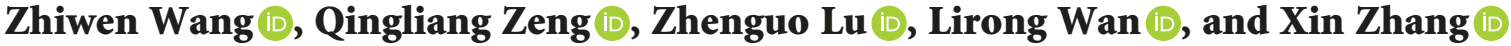 \\ College of Mechanical and Electronic Engineering, Shandong University of Science and Technology, Qingdao 266590, China \\ Correspondence should be addressed to Qingliang Zeng; qlzeng@sdust.edu.cn
}

Received 9 June 2019; Revised 29 July 2019; Accepted 4 September 2019; Published 25 September 2019

Academic Editor: Akhil Garg

Copyright (c) 2019 Zhiwen Wang et al. This is an open access article distributed under the Creative Commons Attribution License, which permits unrestricted use, distribution, and reproduction in any medium, provided the original work is properly cited.

\begin{abstract}
Aiming at the complex nonlinear dynamic problem of cutting hard rock with diamond sawblades, the process of hard rock cutting with a diamond sawblade was studied based on ANSYS/LS-DYNA. A numerical simulation model of a diamond sawblade cutting hard rock with different rotation speeds, feed speeds, and cutting depths was established to study the effects of the cutting parameters on the cutting force and specific cutting energy consumption and on the damage to the rock. The numerical simulation results demonstrated that the feed speed and cutting depth of the diamond saw are quadratically correlated with the cutting force, but the rotation speed is negatively linearly correlated. The damage region of the rock is positively correlated with the feed speed and cutting depth of the diamond sawblade and has a negative correlation with the rotation velocity. The cutting parameters have a great influence on specific cutting energy consumption. Analysis of the relationship among the cutting parameters and the specific cutting energy with multivariate linear fitting indicated that the cutting speed and cutting depth have a great influence on the cutting energy.
\end{abstract}

\section{Introduction}

Natural stone is widely used in the construction industry, and diamond sawblades are mostly used in the process of cutting natural stone. To meet the basic technological demand, improve rock quality, and reduce the cost, the influence of cutting parameters on the cutting performance in the process of rock cutting with diamond sawblades and optimizing the cutting parameters of the sawblade to improve rock quality and reduce the cost were studied. However, research on diamond sawblades is mainly based on research on specific cutting energy consumption, cutting force, and sawblade wear. Yurdakul and Akdas used statistical methods for the prediction of specific cutting energy values [1] and investigated the effects of the cutting mode, cutting depth, and feed speed on the level of consumed power [2]. Konstanty explained the sawing mechanism and structural properties of diamond impregnation and presented a theoretical model of natural stone sawing by means of diamond-impregnated tools [3]. Yu et al. investigated the characteristics of specific energy in the grinding of granite using diamond abrasives [4]. Sun et al. studied the influence of rock properties on segment wear during the cutting of granite using an innovative diamond frame saw prototype and developed a mathematical model to predict segment wear [5]. Karakurt [6] and Sengun and Altindag [7] investigated the cutting force and specific energy during the diamond sawblade rock-cutting process. Hellstrom et al. performed a theoretical and experimental study of the circular sawing process [8]. Yasitli et al. established a discrete-element model of the sawing process and studied the different peripheral speeds and advanced speed in compliance with the actual cutting operation [9]. Asche et al. showed empirical results about the influence of process parameters on tool wear [10] and used an empirical model to predict the variation in the cutting energy and to guide the selection of cutting conditions [11]. Xu et al. studied the force and energy of grinding granite with circular sawing [12] and researched the force ratio by experimental methods [13]. Turchetta established empirical 
models to investigate the influence of cutting conditions on cutting force, and cutting energy was related to the shape of the idealized chip thickness [14]. Zeng et al. researched the influences of diamond sawblades with various cutting speeds and rotation speeds on the damage to the rock [15]. Meanwhile, studies of rock fragmentation have been conducted. $\mathrm{Lu}$ et al. used the numerical code LSDYNA(3D) [16] to numerically simulate fragment separation [17]. Evans proposed the classic and the most authoritative theory of cutting rock, which has been accepted by scholars [18], and obtained the optimum line spacing for cutting picks [19]. Tang studied the statistical rock damage constitutive model to investigate rock damage conditions [20].

Previous studies have obtained fruitful advancements in diamond sawblades, and studies of diamond sawblades for cutting rocks have mostly studied their wear, cutting force, and specific energy consumption. However, there are fewer studies on rock damage with diamond sawblade cutting. Moreover, most studies were carried out by experimental and theoretical methods, and thus, a more efficient numerical simulation method was used to study sawblade rock cutting in this paper. Through the simulation method to research the process of cutting rock with diamond sawblades, the influences of cutting parameters on the performance of sawblades were studied. The simulation results could be used to guide the production of natural stone.

\section{Theoretical and Simulation Studies}

2.1. Theoretical Study. During the cutting of hard rock with a diamond sawblade, the cutting force of the sawblade, which is composed of the normal force, tangential force, and axial force, is very complicated, as shown in Figure 1. The normal force is attributable to the impact of the diamond sawblade on the rock, placing the sawblade and stone on the portions of the contact force. The tangential force is the friction against the sawblade when the rock is cut by the sawblade. The axial force forms as a result of the rock fragments compressing the diamond sawblade. The random distribution of rock fragments on both sides of the diamond sawblade, which is the interaction medium between the sawblade and rock, leads to a large fluctuation in the axial force of the diamond sawblade. Meanwhile, the sawblade rapidly rotates, which will remove the rock debris from sawing, causing the curve of the axial force to fluctuate around the axial force equalling zero.

2.2. Mathematical Expression of Cutting Force. A diamond sawblade cuts hard rock with a constant cutting depth $d_{\mathrm{c}}$, constant feed speed $V_{\mathrm{f}}$ and cutting speed $V_{\mathrm{s}}$. The rock is cut by a diamond sawblade with the down-cut style. When cutting rock with a diamond sawblade, the tangential and normal forces are not easy to obtain directly, but the horizontal and vertical forces are relatively easy to obtain. The process of solving for the normal and tangential force by horizontal and vertical forces is as follows:

The relation of forces can be expressed as follows:

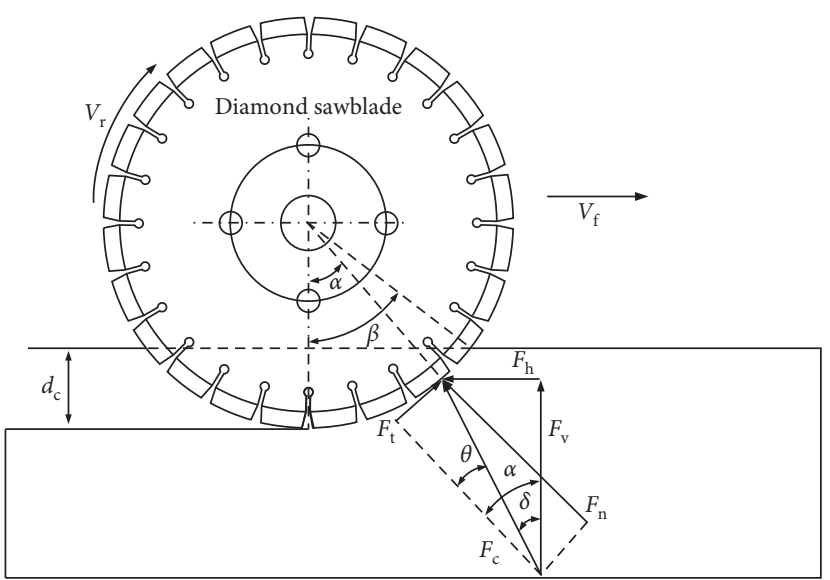

FIGURE 1: The model for cutting hard rock with a diamond sawblade: $F_{\mathrm{v}}=$ vertical force, $F_{\mathrm{h}}=$ horizontal force, $F_{\mathrm{t}}=$ tangential force, $F_{\mathrm{n}}=$ normal force, $V_{\mathrm{f}}=$ feed speed, $V_{\mathrm{r}}=$ rotation speed, and $d_{\mathrm{c}}=$ cutting depth.

$$
\begin{aligned}
F_{\mathrm{c}} & =\sqrt{F_{\mathrm{h}}^{2}+F_{\mathrm{v}}^{2}}, \\
F_{\mathrm{h}}^{2}+F_{\mathrm{v}}^{2} & =F_{\mathrm{n}}^{2}+F_{\mathrm{t}}^{2},
\end{aligned}
$$

where $F_{\mathrm{c}}$ is the cutting force, $F_{\mathrm{h}}$ is the horizontal force, $F_{\mathrm{v}}$ is the vertical force, $F_{\mathrm{t}}$ is the tangential force, $F_{\mathrm{n}}$ is the normal force, and $d$ is the sawblade diameter. Therefore, the relationship of force is shown in Figure 1, which can be obtained from the geometric relation diagram, as follows:

$$
\begin{aligned}
& \beta=\cos ^{-1}\left(1-\frac{2 d_{\mathrm{c}}}{d}\right), \\
& \delta=\tan ^{-1}\left(\frac{F_{\mathrm{h}}}{F_{\mathrm{v}}}\right) .
\end{aligned}
$$

It can be concluded from the graph that the tangential forces $F_{\mathrm{t}}$ and normal force $F_{\mathrm{n}}$ in the rock cutting process can be expressed as follows:

$$
\begin{aligned}
F_{\mathrm{t}} & =F_{\mathrm{c}} \sin (\alpha-\delta), \\
F_{\mathrm{n}} & =F_{\mathrm{c}} \cos (\alpha-\delta), \\
F_{\mathrm{t}} & =F_{\mathrm{v}} \sin \alpha-F_{\mathrm{h}} \cos \alpha, \\
F_{\mathrm{n}} & =F_{\mathrm{v}} \cos \alpha-F_{\mathrm{h}} \sin \alpha, \\
\alpha & =\varepsilon+\delta, \\
\alpha & =k \beta, \\
k & =\frac{\varepsilon+\delta}{\beta} .
\end{aligned}
$$

Among them, the value of $k$ is determined by the contact position between the diamond sawblade and the rock. Some scholars believe that $k=0.5$ [21], but after further study, the calculation of the tangential and normal forces is found to be inaccurate. Through the study of Guo, the research was 


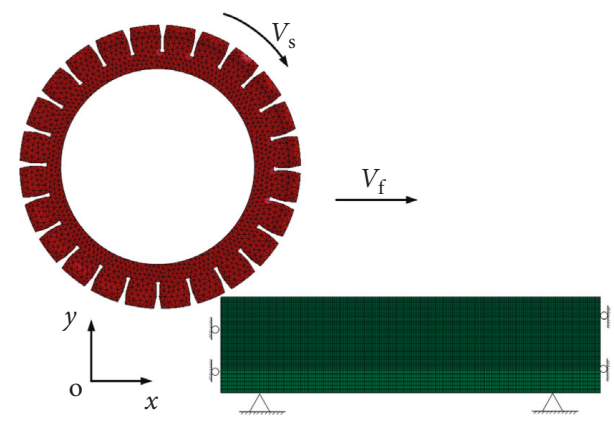

FIGURE 2: Rock-cutting model of the rock with diamond sawblade.

relatively accurate when $k \approx 0.67$ [22], and thus, $k=0.7$ in this paper.

In summary, the calculation formulas of the tangential and normal forces in the process of cutting hard rock with a diamond sawblade can be obtained as follows:

$$
\begin{aligned}
F_{\mathrm{t}}= & F_{\mathrm{v}} \sin \left[k \cos ^{-1}\left(1-\frac{2 d_{\mathrm{c}}}{d}\right)\right] \\
& -F_{\mathrm{h}} \cos \left[k \cos ^{-1}\left(1-\frac{2 d_{\mathrm{c}}}{d}\right)\right], \\
F_{\mathrm{n}}= & F_{\mathrm{v}} \cos \left[k \cos ^{-1}\left(1-\frac{2 d_{\mathrm{c}}}{d}\right)\right] \\
& +F_{\mathrm{h}} \sin \left[k \cos ^{-1}\left(1-\frac{2 d_{\mathrm{c}}}{d}\right)\right] .
\end{aligned}
$$

2.3. Establishing the Numerical Simulation Model. The diamond sawblade-rock model was established with ANSYS/ LS-DYNA(3D). The diameter of the diamond sawblade was $380 \mathrm{~mm}$, and the diamond sawblade had 24 blocks $40 \mathrm{~mm}$ in length, $15 \mathrm{~mm}$ in height, and $3.4 \mathrm{~mm}$ in thickness. The rock was a cuboid block $500 \mathrm{~mm}$ in length, $115 \mathrm{~mm}$ in width, and $150 \mathrm{~mm}$ in height. The 3D 8-node hexahedron element was used to mesh the rock. The meshing of the diamond sawblade and rock was carried out by the meshing tool meshwork of ANSYS/LS-DYNA. The eight-node hexahedron element SOLID164 was adopted to improve the accuracy of the calculation and to accurately simulate the rockcutting force and crushing process. The method of local thinning for the rock model was used with a smaller mesh in the cutting area and a larger mesh in the noncutting area. The diamond sawblade was set as a rigid body, and the middle part of the noncutting part was removed to reduce the number of grids and improve the calculation efficiency.

Constraints were added to the rock model. Full constraints were added to the rock bottom surface, $y$-axial constraints were added to the front and back surfaces, and $x$ direction constraints were added to the left and right surfaces of the rock. Nonreflecting boundaries were implemented for all of the rock surfaces except the upper surface, which can prevent stress reflection from affecting the numerical simulation results. Displacement constraints along
TABLE 1: The main material parameters of rock.

\begin{tabular}{lccccc}
\hline$\rho_{0}$ & Shear & B0 & B1 & T1 & FC \\
\hline $2760 \mathrm{~kg} / \mathrm{m}^{3}$ & $1.68 e 10$ & 0.9 & 0.9 & $4.539 e 10$ & $4.8 e 7$ \\
$\mathrm{EC}$ & $\mathrm{ET}$ & $\mathrm{FS}^{*}$ & $\mathrm{FT}^{*}$ & PEL & PCO \\
$3.0 e-8$ & $3.0 e 22$ & 0.18 & 0.1 & $2.33 e 7$ & $6 e 8$ \\
$\mathrm{E} 0 \mathrm{C}$ & $\mathrm{E} 0 \mathrm{~T}$ & $\mathrm{GC}^{*}$ & $\mathrm{GT}^{*}$ & $\mathrm{D} 1$ & $\mathrm{D} 2$ \\
$3 e-9$ & $3 e 22$ & 0.53 & 0.7 & 0.04 & 1 \\
\hline
\end{tabular}

the $y$ - and $z$-axes and rotation constraints around the $x$ - and $z$-axes were added to the diamond sawblade. The sawblade moved uniformly and linearly along the forward direction of the $x$-axis and rotated around the central axis as shown in Figure 2.

The RHT constitutive model, which contains the damage constitutive relation and erosion pattern, was chosen as the hard-rock material model, and the main material parameters of the rock are shown in Table 1. The contact form of the diamond sawblade and the rock was defined as the eroding surface and surface (ERODING SURFACE AND SURFACE) contact and automatic universal contact (AUTOMATIC_GENRAL). In the process of cutting rock with a diamond sawblade, the deformity element may appear. It is necessary to control the hourglass energy to prevent the influence of negative volume without the method of mass scaling to ensure the accuracy of the calculation. Based on ensuring the calculation accuracy, the element quantity of the rock model is reduced. The rock was meshed by local refinement, and the cutting area of the diamond sawblade was meshed with smaller elements. The feed speed of the diamond sawblade was set as $0.2,0.225$, $0.25,0.3$, and $0.35 \mathrm{~m} / \mathrm{min}$; the rotation speed was set as $1000,1500,2000,2500$, and $3500 \mathrm{r} / \mathrm{min}$; and the cutting depth of the diamond sawblade was set as 1, 3, 5, 7, and $9 \mathrm{~cm}$. We set the simulation time as 2.5 minutes, and each step lasts $1 \mathrm{~s}$. The solver in LS-DYNA has no limits for CPU cores, and the results of each step are automatically exported as a d3plot file; the diamond sawblade rockcutting simulation model is efficiently performed on a workstation for $21 \mathrm{~h}$.

\section{Numerical Results and Discussion}

3.1. Grid Independence Validation. To fully illustrate the reliability of the numerical simulation results and the scientific basis of mesh generation, the relation rates of the vertical force and horizontal force of the numerical simulation in different numerical grids were used to judge the grid independence. When the relative change rate is within the set range, it can be concluded that the results are accurate and that the mesh is scientifically based. The number of rock grids has a great influence on the numerical simulation results, so it is necessary to test the independence of the rock grids. Finally, a reasonable mesh density is selected to test the grids of the rock mesh. The relative variation in horizontal and vertical forces under different mesh numbers of the rock is plotted in Figure 3.

When the mesh number reached 231340, the relative change rate of the vertical and horizontal forces was less than 


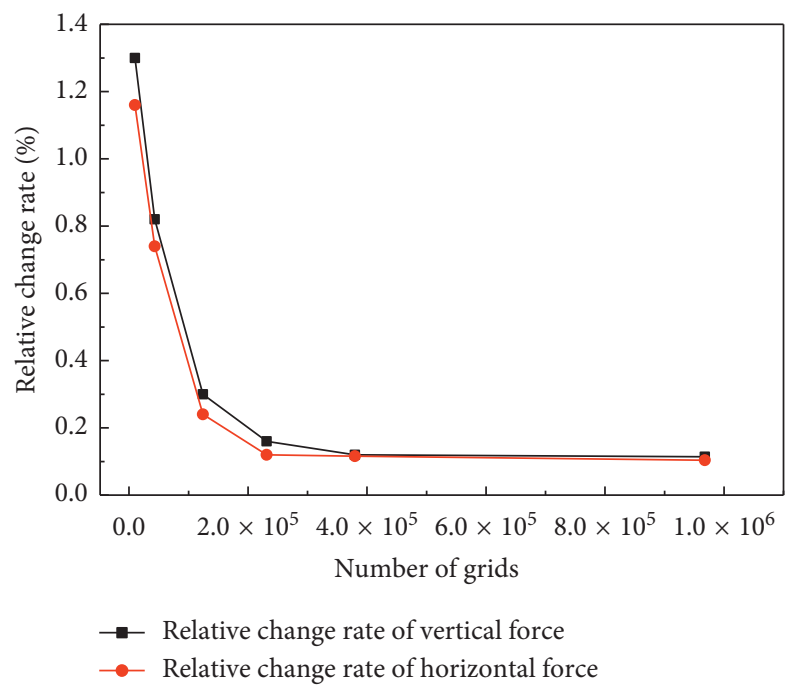

Figure 3: Independence test of the rock mesh density.

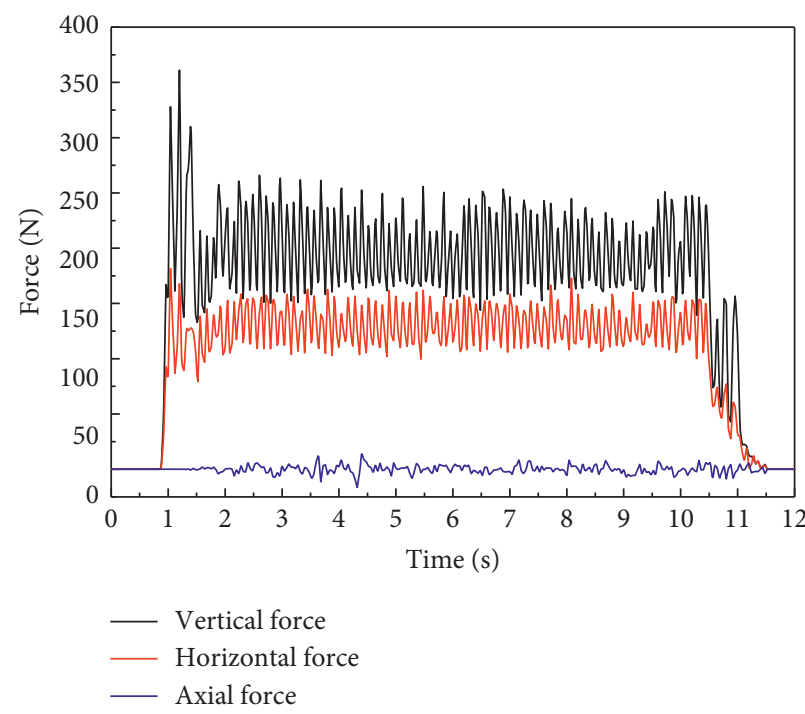

(a)

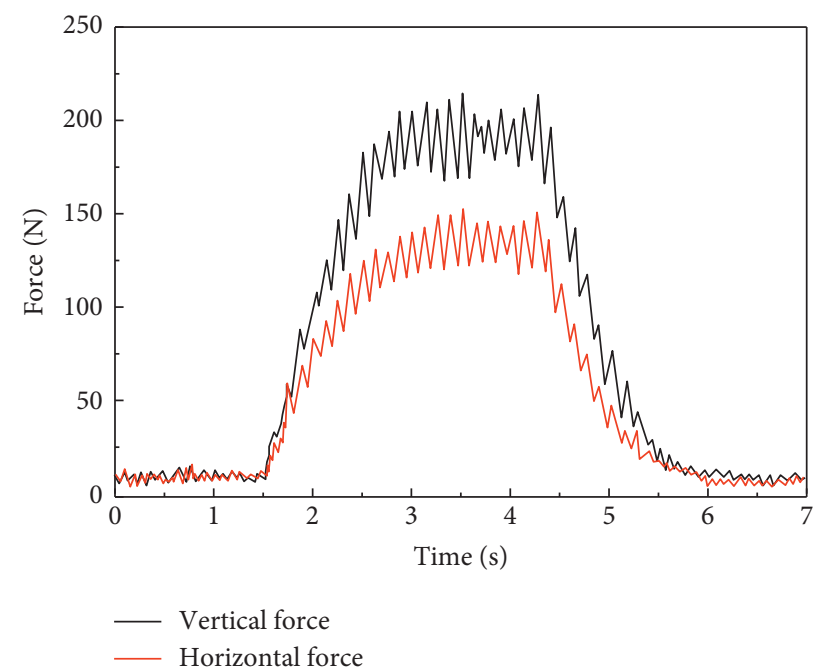

(b)

FIGURE 4: The results of the numerical simulation and experiment.

$0.2 \%$, and the relative change rate was controlled to within $0.2 \%$. Considering the accuracy of the results and computer performance, the number of grids should be more than 231340 .

3.2. Calibration and Verification. The accuracy of the numerical simulation is verified by comparing the numerical simulation with experimental data. The results of the numerical simulation with a peripheral speed of the diamond sawblade of $30 \mathrm{~m} / \mathrm{s}$, a feed speed of $3 \mathrm{~m} / \mathrm{min}$ and a cutting depth of $15 \mathrm{~mm}$ are presented in Figure 4(a), and the results of the experiment [13] under the same cutting conditions are shown in Figure 4(b). The average values of the vertical force and horizontal force curves at the stable stage in the experiments are $190.06 \mathrm{~N}$ and $137.12 \mathrm{~N}$, respectively, and those of the numerical simulation are $195.26 \mathrm{~N}$ and $131.35 \mathrm{~N}$, respectively. Owing to the low frequency of the data acquisition in the experiment, the sudden increase in the force curve at the moment of contact between the sawblade and the rock was not collected. This result indicates that the numerical simulation model accurately simulates the diamond sawblade cutting rock.

3.3. Failure Mode of Rock. To research the rock failure mode, two test point elements at different positions were selected, and the frequency of the extracting force value improved. A diamond sawblade cutting rock with a high rotation speed and cutting speed causes diverse rock failure modes. The diamond sawblade interacts with the rock, and the cutting force acts on the rock, causing rock failure and fragmentation. To understand the failure forms clearly, the pressure and shear force must be extracted. The pressure is positive, 


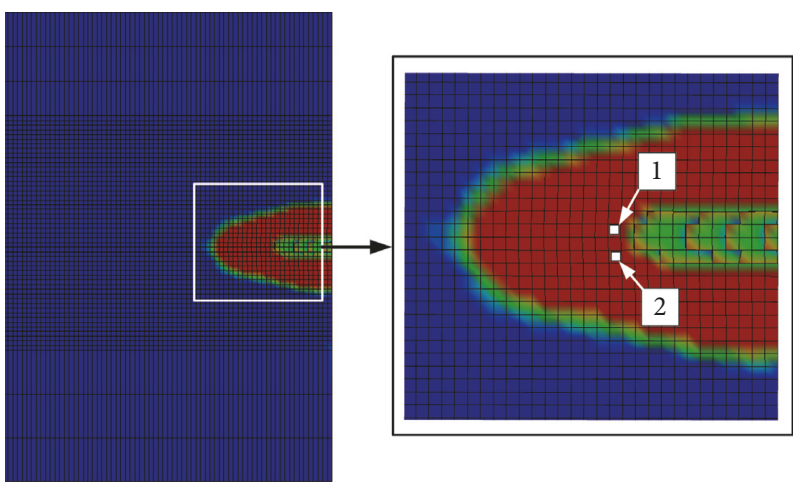

Figure 5: The test point elements in the failure mode.

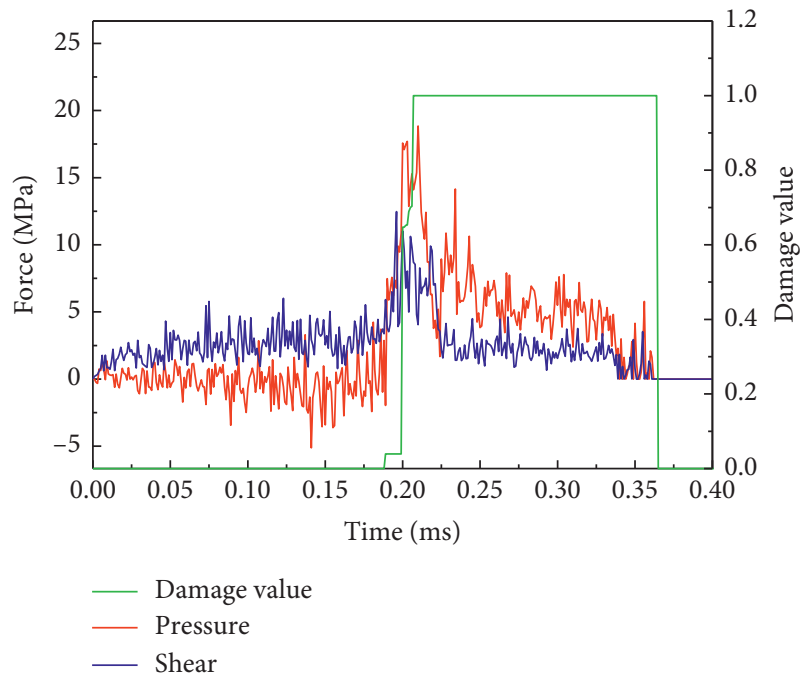

(a)

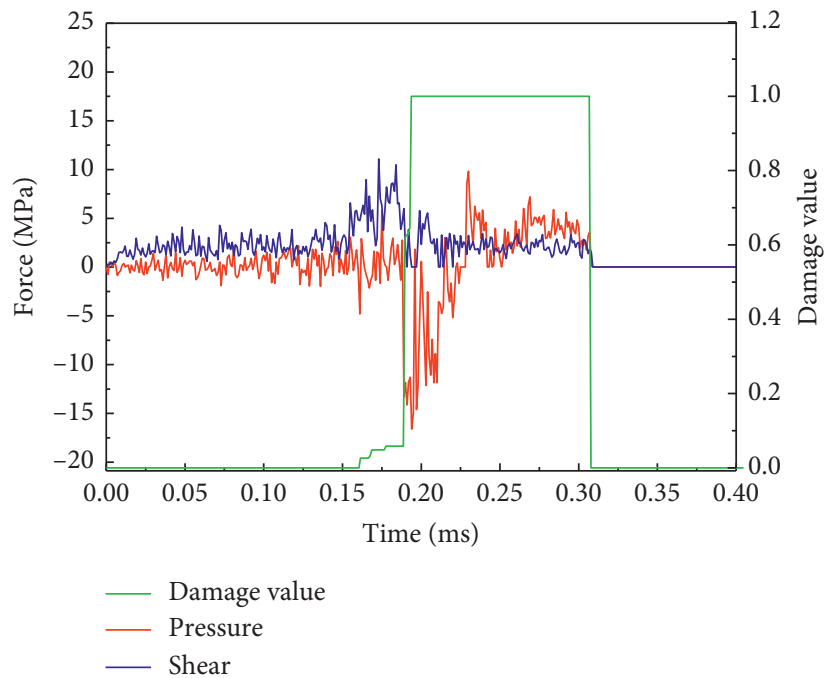

(b)

FIgURE 6: The variations in the stress and corresponding damage and shear with time.

which means that the force is a compressive force; negative pressure denotes a tensile force.

Two points in the broken zone were selected to investigate the failure mode of cutting rock with a diamond sawblade, and the results are presented in Figure 5. For test element 1 in the broken zone, the pressure force, shear force, and damage value versus time are shown in Figure 6(a). For test point element 1 , the damage value increased to 1 within $0.02 \mathrm{~ms}$, the compressive force reached $18.8 \mathrm{MPa}$, and the maximum shear force reached $12.47 \mathrm{MPa}$. Therefore, test point 1 is compressive failure. As shown in the Figure 6(b), the tensile force of the test point 2 reached $16.6 \mathrm{MPa}$, while the shear force reached $11.2 \mathrm{MPa}$, and the damage value reached 1 , which means the element is in tensile failure.

3.4. Influences of the Cutting Parameters on Cutting Force. The cutting force of the diamond sawblade is mainly composed of the tangential force, normal force, and axial force. Diamond sawblades cut hard rock with a feed speed of $0.25 \mathrm{~m} / \mathrm{min}$, a rotation speed of $1500 \mathrm{r} / \mathrm{min}$, and a cutting depth of $5 \mathrm{~cm}$. The cutting force, tangential force, normal force, and axial force curves of a diamond sawblade in the cutting process are shown in Figure 7. The cutting force, normal force, tangential force, and axial force appear simultaneously when the diamond sawblade is in contact with the hard rock. The normal force and tangential force are the main components of the cutting force of the diamond sawblade. The change tendency of the normal force is similar to that of the cutting force. While the diamond sawblade is touching the rock, the normal force begins to increase rapidly and beyond the fluctuation of stable cutting. The fluctuation ranges of the initial normal and the tangential force are larger than those during steady cutting. The cutting force and normal force of the diamond sawblade decrease rapidly to a stable fluctuation range as the cutting distance increases and fluctuates within a certain range. The axial force appears when the diamond sawblade touches the rock. The fluctuation amplitude of the axial force increases with the cutting distance at the beginning. The axial force fluctuation is stable in a certain range after a certain cutting distance.

When the diamond sawblade was cutting rock with a uniform feed speed, rotation speed, and cutting depth, the 


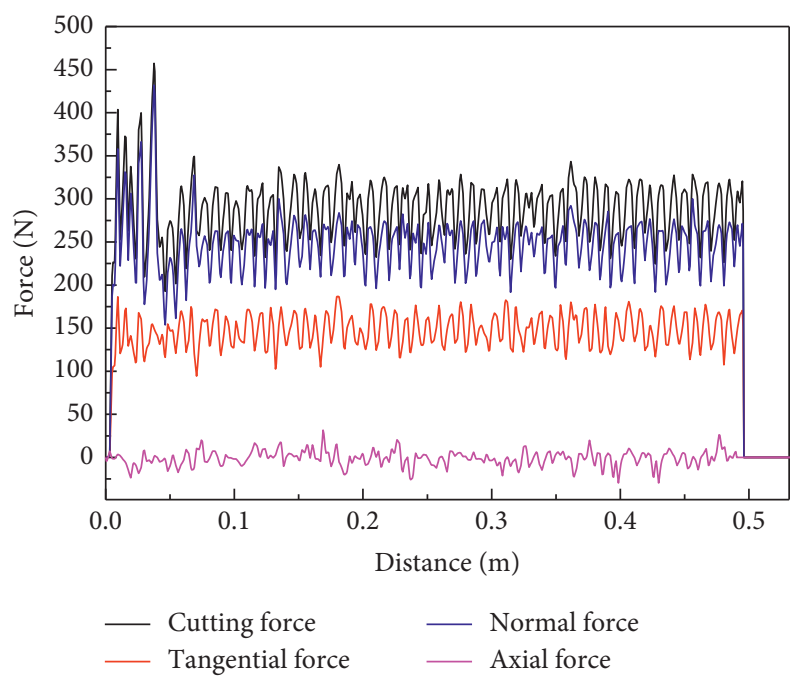

FIgURE 7: Force curves of a diamond sawblade cutting hard rock.
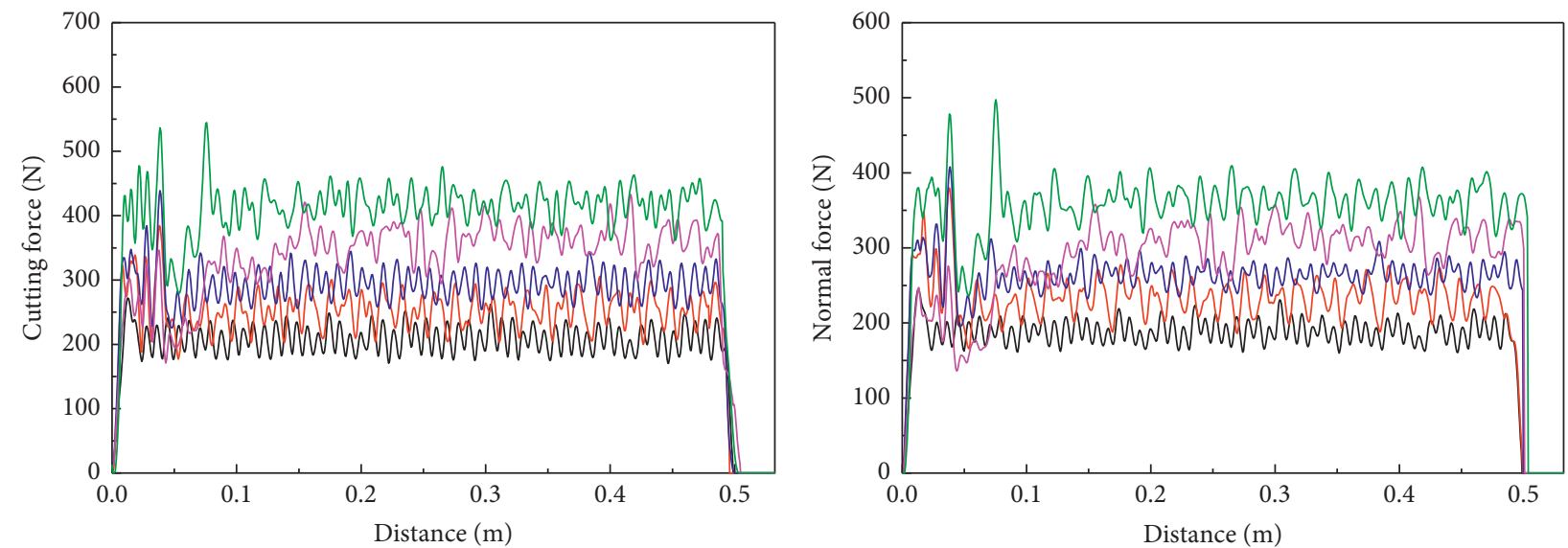

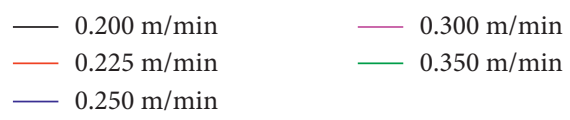

(a)
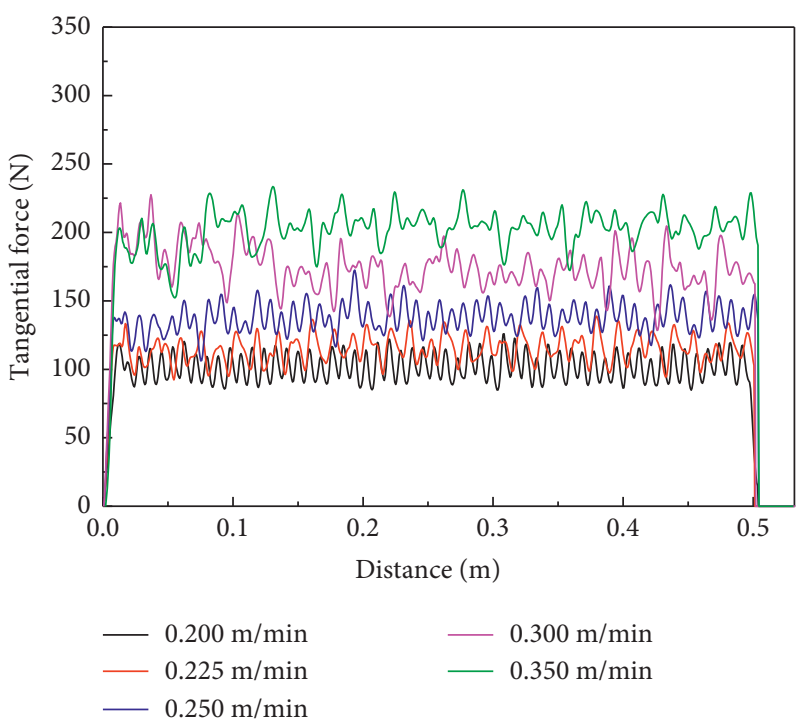

(c)

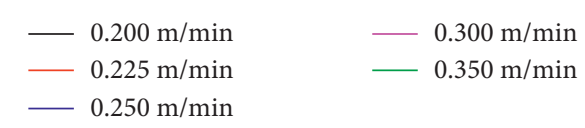

(b)

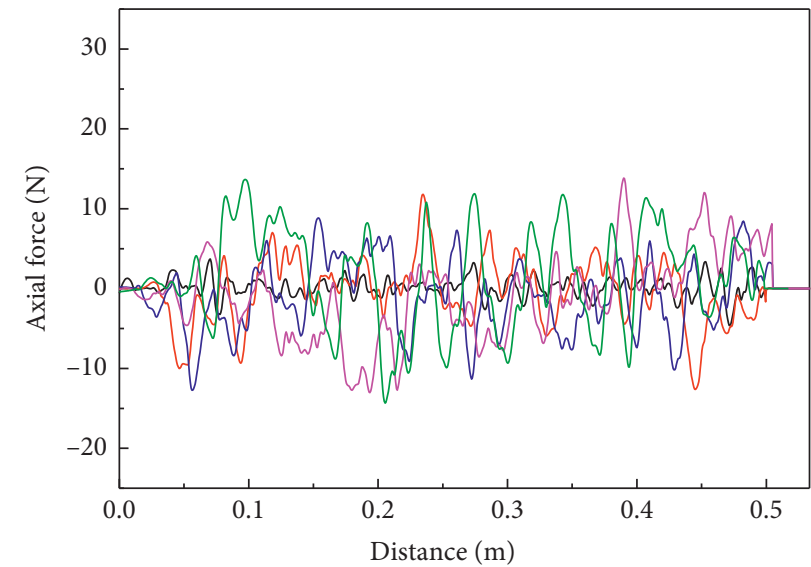

$-0.200 \mathrm{~m} / \mathrm{min}$
$-0.225 \mathrm{~m} / \mathrm{min}$
$-0.250 \mathrm{~m} / \mathrm{min}$

- $0.300 \mathrm{~m} / \mathrm{min}$

- $0.350 \mathrm{~m} / \mathrm{min}$

(d)

FIGURE 8: Various forces versus distance for different feed speeds: (a) cutting forces, (b) normal forces, (c) tangential forces, and (d) axial forces. 


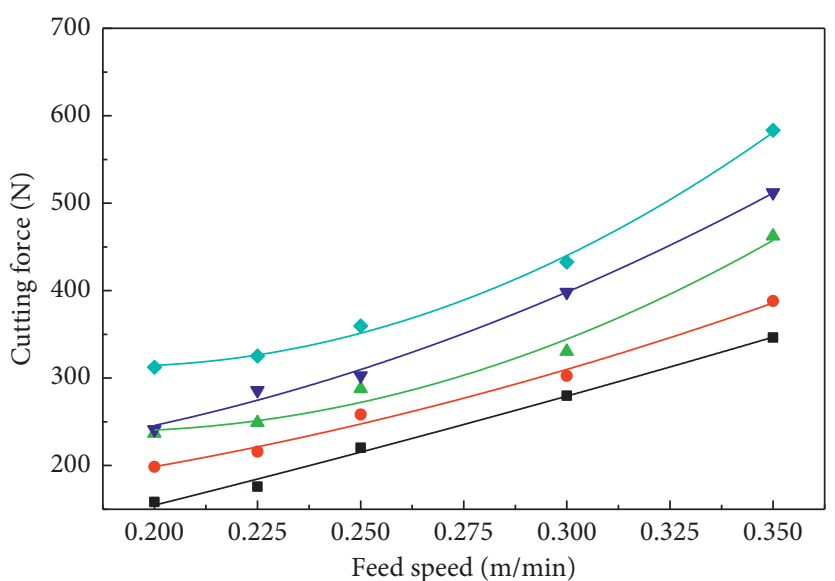

Cutting depth

- $1 \mathrm{~cm} y=679.30881 x^{2}-907.81865 x-54.09081 R^{2}=0.99031$

- $3 \mathrm{~cm} y=2713.0156 x^{2}-243.99601 x-138.9724 R^{2}=0.98218$

$\Delta 5 \mathrm{~cm} y=8143.6473 x^{2}-3032.1725 x-521.2574 R^{2}=0.97098$

จ $7 \mathrm{~cm} y=4939.8507 x^{2}-945.01311 x-237.2522 R^{2}=0.99158$

- $9 \mathrm{~cm} y=10401.319 x^{2}-3945.0613 x-687.5376 R^{2}=0.99456$

(a)

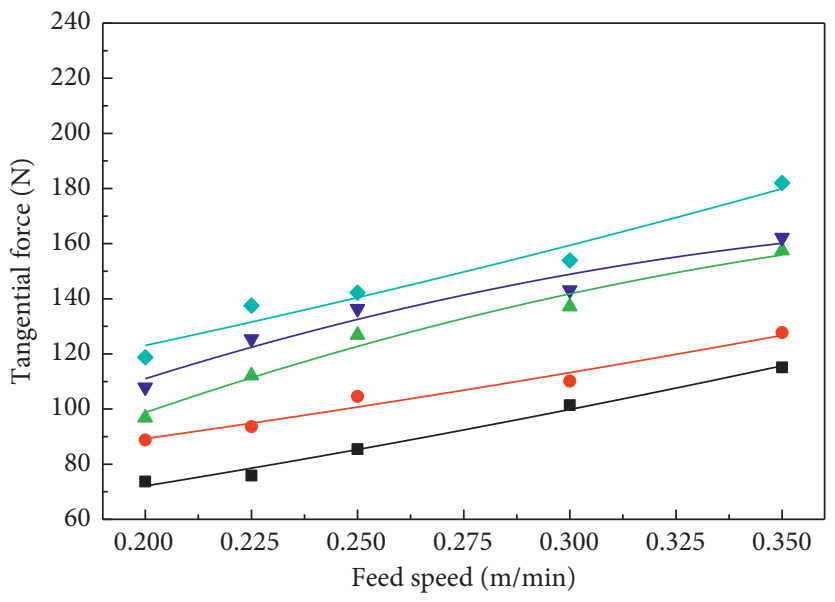

Cutting depth

- $1 \mathrm{~cm} y=261.83781 x^{2}+146.66586 x+32.28725 R^{2}=0.97977$

- $3 \mathrm{~cm} \quad y=206.2899 x^{2}+136.32768 x+53.74607 \quad R^{2}=0.94283$

$\Delta 5 \mathrm{~cm} \quad y=-987.9394 x^{2}+924.60584 x-46.68878 R^{2}=0.95811$

$\checkmark 7 \mathrm{~cm} \quad y=-1025.041 x^{2}+657.20198 x+87.83495 R^{2}=0.91282$

- $9 \mathrm{~cm} y=1348.9629 x^{2}+746.38281 x+99.75396 R^{2}=0.91574$

(c)

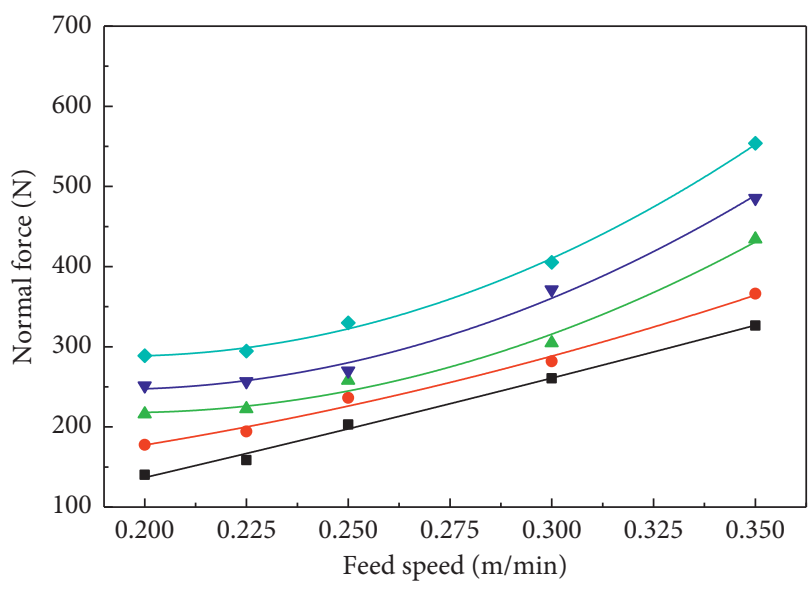

Cutting depth

- $1 \mathrm{~cm} y=506.20093 x^{2}+988.05198 x-81.04226 R^{2}=0.99058$

- $3 \mathrm{~cm} y=2743.4243 x^{2}-262.97548 x-120.3091 R^{2}=0.98424$

$\triangle 5 \mathrm{~cm} y=8831.9396 x^{2}-3439.7985 x-552.8032 R^{2}=0.97974$

V $7 \mathrm{~cm} y=9575.1444 x^{2}-3656.7391 x-595.8696 R^{2}=0.98797$

$\checkmark 9 \mathrm{~cm} y=10842.891 x^{2}-4206.7071 x+696.4016 R^{2}=0.99597$

(b)

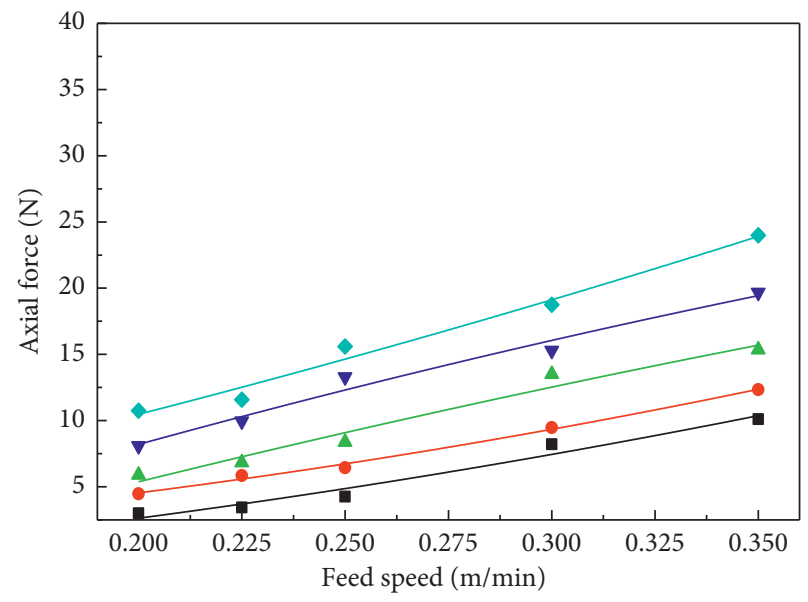

Cutting depth

- $1 \mathrm{~cm} y=69.03218 x^{2}+13.65604-2.86419 \quad R^{2}=0.93853$

- $3 \mathrm{~cm} \quad y=83.28451 x^{2}+6.33742-0.05469 \quad R^{2}=0.99095$

$\triangle 5 \mathrm{~cm} \quad y=-53.8494 x^{2}+98.37476-12.13995 R^{2}=0.94212$

> $7 \mathrm{~cm} y=-72.4463 x^{2}+114.7170-11.84153 R^{2}=0.95828$

- $9 \mathrm{~cm} y=62.12383 x^{2}+55.36997-3.08289 \quad R^{2}=0.96569$

(d)

FIGURE 9: Relationships between the mean forces and the feed speed: (a) relationship between the mean cutting force and feed speed, (b) relationship between the mean normal force and feed speed, (c) relationship between the mean tangential force and feed speed, and (d) relationship between the mean axial force and feed speed.

cutting force, normal force, and tangential force appeared together as the diamond sawblade contacted the hard rock. The main cause of the phenomenon is that the rotation speed and feed speed are higher. The sawblade has a large impact on the rock as the sawblade contacts the rock. In the instant of contact between the sawblade and rock, the peak of the normal force and the peak of the cutting force increase beyond the maximum values of the fluctuation ranges during stable cutting. In actual production, the sawblade contacts the rock with a small feed speed and then increases the feed speed slowly to meet the requirements of the actual work. At the initial stage of cutting, the axial force of the sawblade was smaller, and it increased until it reached a stable fluctuation range as the cutting distance increased. With the distance of the sawblade cutting into the rock increasing, the overlapping area between the sawblade and the rock increased and reached the maximum value, and the axial action increased until reaching the maximum, which caused the axial force to increase and reach the maximum stability fluctuation range as the force changed. 


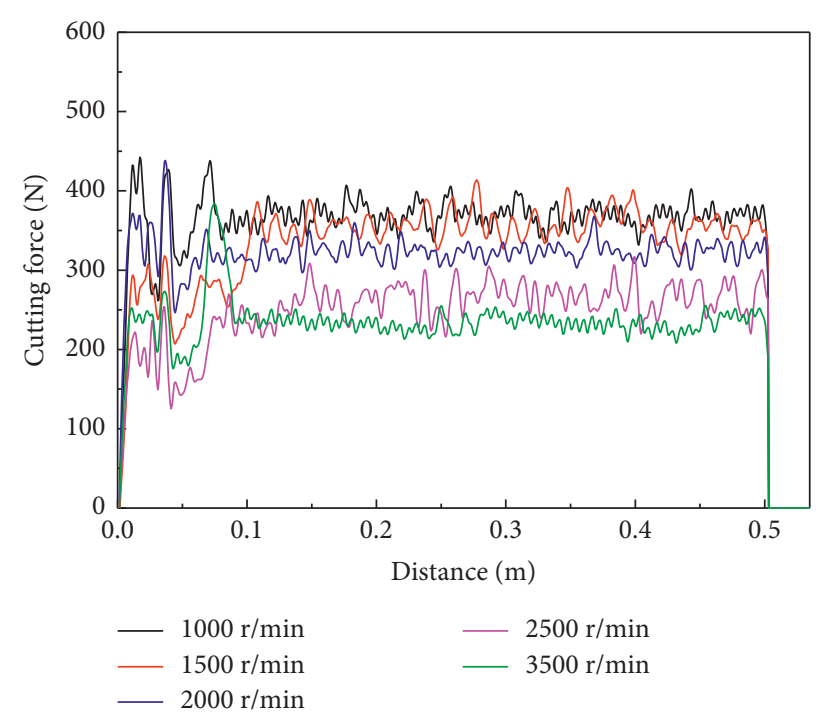

(a)

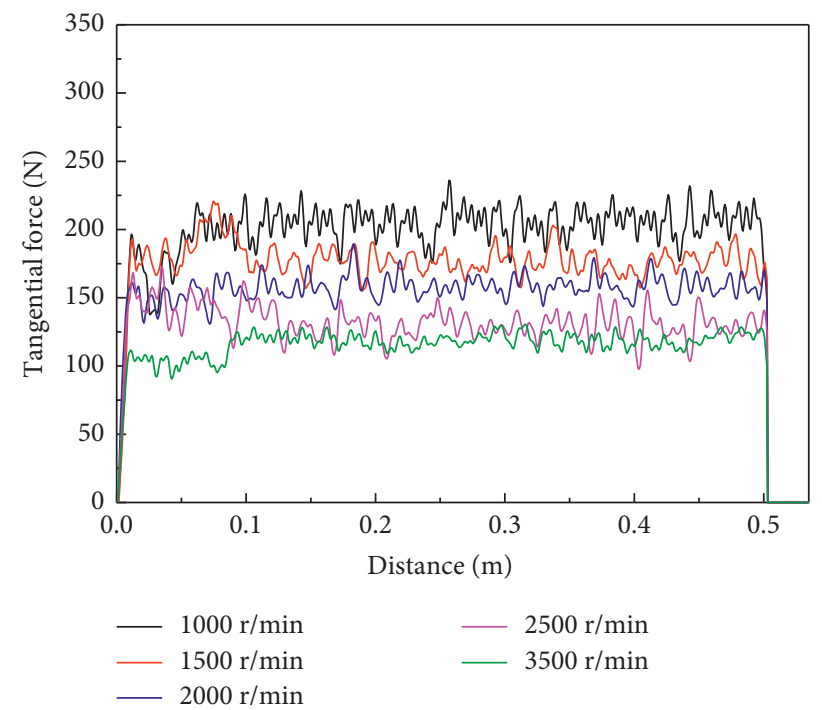

(c)

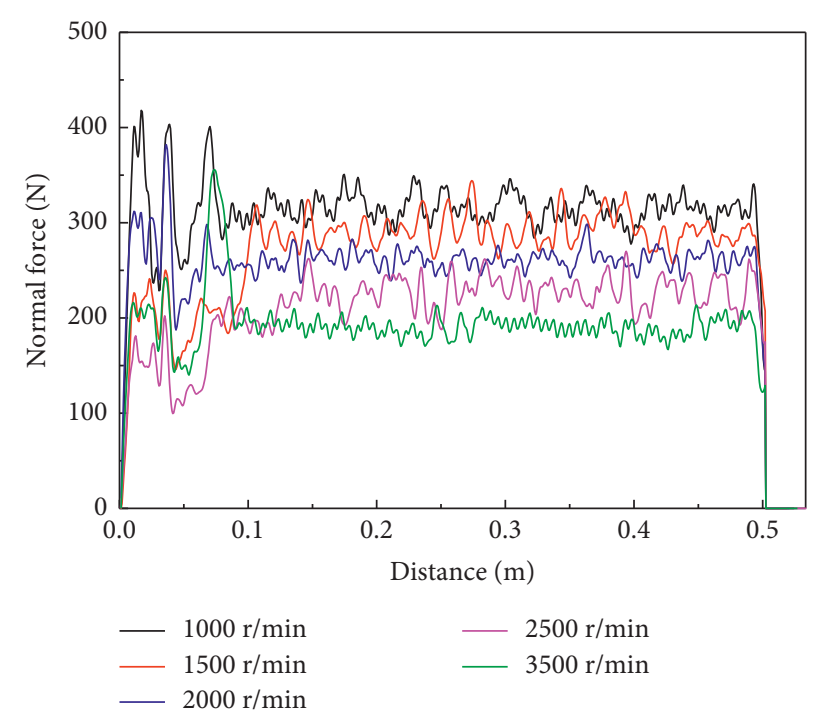

(b)

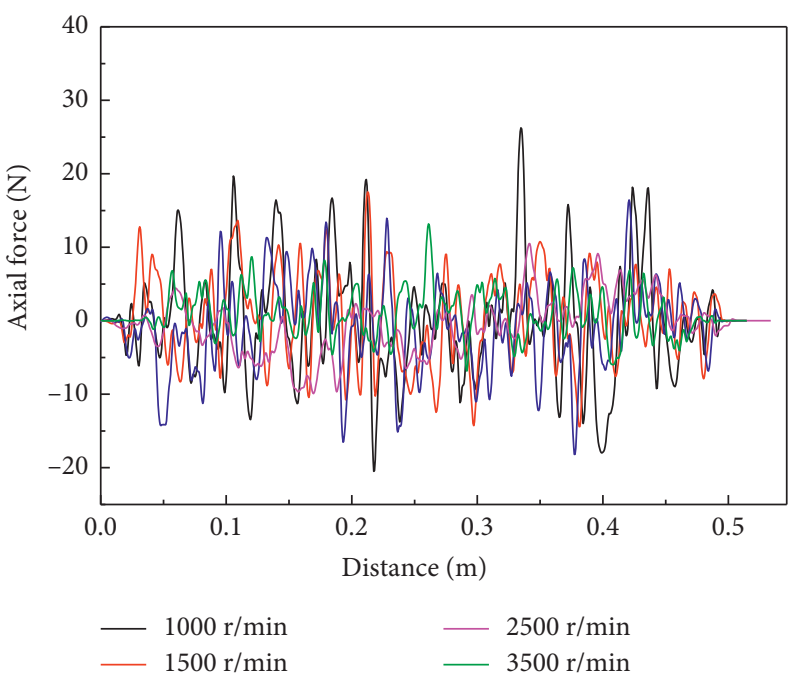

(d)

FIGURE 10: Variations in forces with distance: (a) variation in the cutting force with distance for different rotation speeds, (b) variation in the normal force with distance for different rotation speeds, (c) variation in the tangential force with distance for different rotation speeds, and (d) variation in the axial force with distance for different rotation speeds.

The curves of the cutting forces, normal forces, tangential forces, and axial forces when the diamond sawblade cut the hard rock with a rotation speed of $2000 \mathrm{r} / \mathrm{min}$, a cutting depth of $5 \mathrm{~cm}$, and feed speeds of $0.2,0.225,0.25,0.3$, and $0.35 \mathrm{~m} / \mathrm{min}$ are plotted in Figure 8 . It is obvious that the force of the diamond sawblade increases with increasing feed speed. Additionally, the fluctuation amplitude of force increases with increasing feed speed.

The following is a discussion of the influence of the feed speed on the cutting force of the diamond sawblade cutting rock with a constant rotation speed and cutting depth. The average cutting forces, average normal forces, average tangential forces, and average axial forces were fitted with the feed speeds, as shown Figure 9. The average cutting force, average normal force, average tangential force, and average axial force are called the average force. It is clear that the average force increased with increasing feed speed. The relational expression among the average force and the feed speed was $y=A x^{2}+B x+C$. The functional expressions of the feed speed and forces are shown in Figure 9.

To research the influence of the rotation speed on the force of the diamond sawblade cutting rock, the diamond sawblade cut the rock with a feed speed of $0.25 \mathrm{~m} / \mathrm{min}$, a cutting depth of $5 \mathrm{~cm}$, and rotation speeds of 1000,1500 , 2000,2500 , and $3500 \mathrm{r} / \mathrm{min}$ in the simulations. The force curves of the diamond sawblade versus cutting distance are shown in Figure 10, and the cutting force is closely related to the rotation speed. At the instant that the diamond 

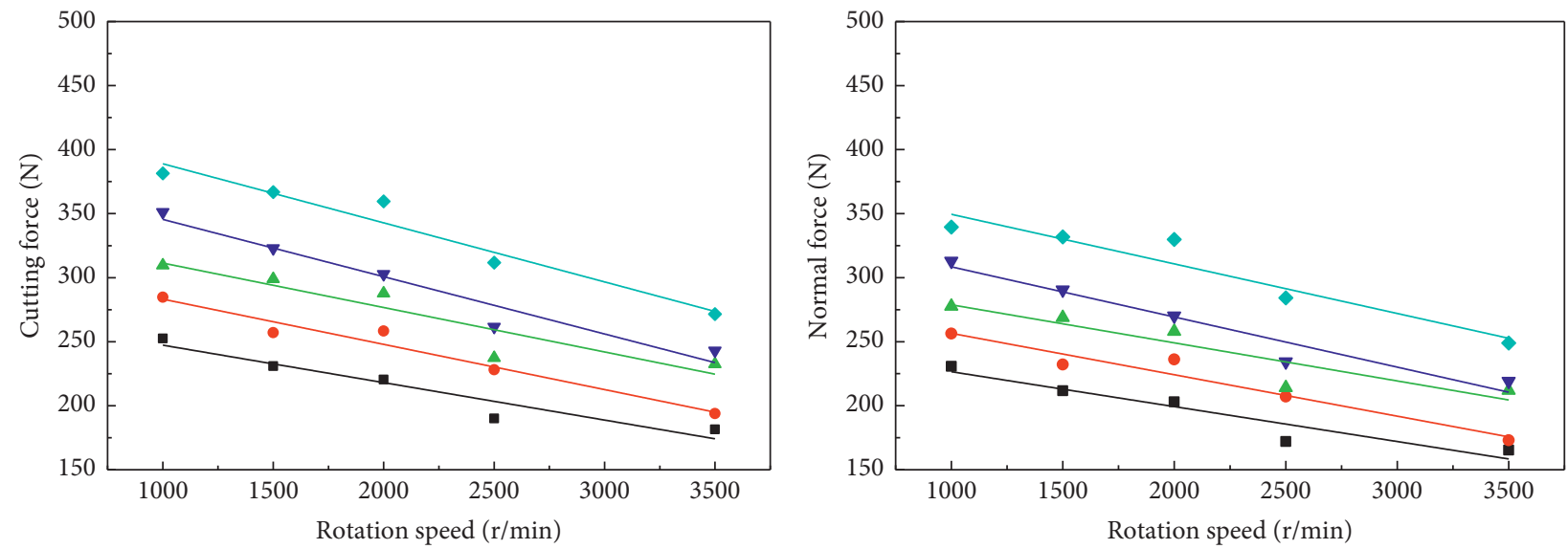

Cutting depth

$\begin{array}{lll}\text { - } 1 \mathrm{~cm} & y=-0.2925 x+276.54448 & R^{2}=0.89560 \\ \text { - } 3 \mathrm{~cm} & y=-0.35317 x+318.5453 & R^{2}=0.94080 \\ \text { - } 5 \mathrm{~cm} & y=-0.3471 x+346.11614 & R^{2}=0.82107 \\ \text { - } 7 \mathrm{~cm} & y=-0.44736 x+390.2348 & R^{2}=0.93128 \\ \text { - } 9 \mathrm{~cm} & y=-0.46126 x+435.0672 & R^{2}=0.93460\end{array}$

(a)

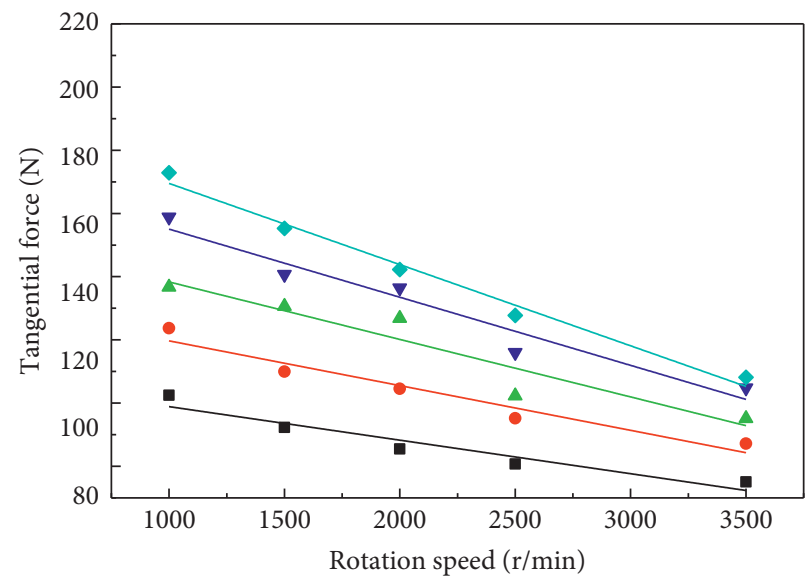

Cutting depth

$\begin{array}{lll}\text { - } 1 \mathrm{~cm} & y=-0.10611 x+109.48813 & R^{2}=0.89902 \\ \text { - } 3 \mathrm{~cm} & y=-0.14156 x+133.84605 & R^{2}=0.92672 \\ \text { - } 5 \mathrm{~cm} & y=-0.1819 x+156.52273 & R^{2}=0.87126 \\ \text { จ } 7 \mathrm{~cm} & y=-0.21553 x+176.60102 & R^{2}=0.93122 \\ \text { - } 9 \mathrm{~cm} & y=-0.25691 x+195.19971 & R^{2}=0.98132\end{array}$

(c)
Cutting depth

- $1 \mathrm{~cm} \quad y=-0.27252 x+253.79654 \quad R^{2}=0.88212$

- $3 \mathrm{~cm} y=-0.32342 x+288.87452 \quad R^{2}=0.92887$

$\Delta 5 \mathrm{~cm} y=-0.29729 x+308.54666 \quad R^{2}=0.80291$

> $7 \mathrm{~cm} \quad y=-0.39168 x+347.63917 \quad R^{2}=0.92615$

- $9 \mathrm{~cm} y=-0.38722 x+2388.2077 \quad R^{2}=0.88322$

(b)

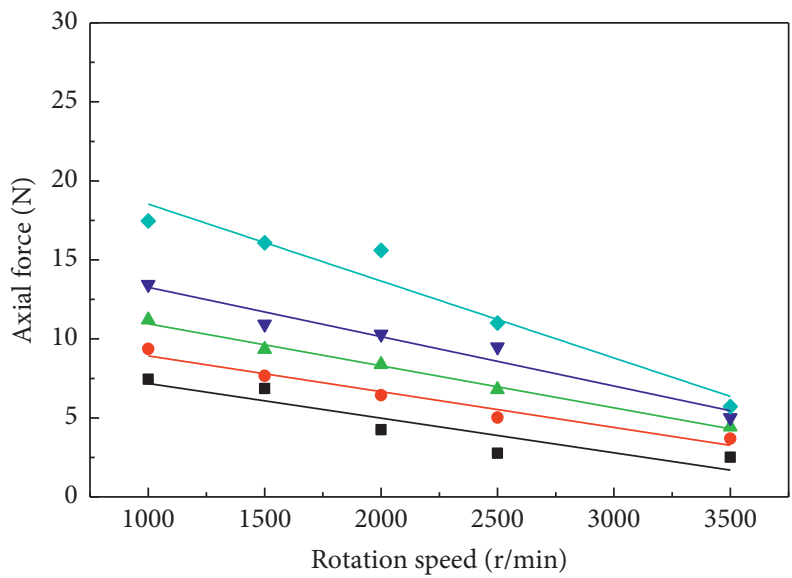

Cutting depth

- $1 \mathrm{~cm} \quad y=-0.02192 x+9.36881 R^{2}=0.80062$

- $3 \mathrm{~cm} y=-0.02265 x+11.1899 R^{2}=0.95279$

$\Delta 5 \mathrm{~cm} \quad y=-0.0266 x+13.61991 R^{2}=0.99051$

จ $7 \mathrm{~cm} \quad y=-0.03124 x+16.390 \quad R^{2}=0.94116$

- $9 \mathrm{~cm} \quad y=-0.04868 x+23.3982 \quad R^{2}=0.92311$

(d)

FIGURE 11: Relationships between the mean force and rotation speed: (a) relationship between the mean cutting force and rotation speed, (b) relationship between the mean normal force and rotation speed, (c) relationship between the mean tangential force and rotation speed, and (d) relationship between the mean axial force and rotation speed.

sawblade comes in contact with the rock, the impact leads to an instant increase in the peak force. The main reason is that the rotation speed of the diamond sawblade increases, the cutting speed increases, and the sawblade cutting the hard rock at a constant speed and depth causes the impact force to increase by a larger margin. However, it is obvious that the cutting force, normal force, tangential force, and axial force of the diamond sawblade decreased with increasing rotation speed when the diamond sawblade was cutting stably.
With different cutting depths, the rotation speed was fit with the mean of the cutting force, the normal force, the tangential force, and the axial force to obtain a fitting curve and the functional expressions, which are shown in Figure 11. The relationship expression between the rotation speed and the force is $y=A x+b$. It can be concluded that the rotation speed is linearly related to various forces, and the functional expression and correlation coefficient of each curve are shown in Figure 11. 


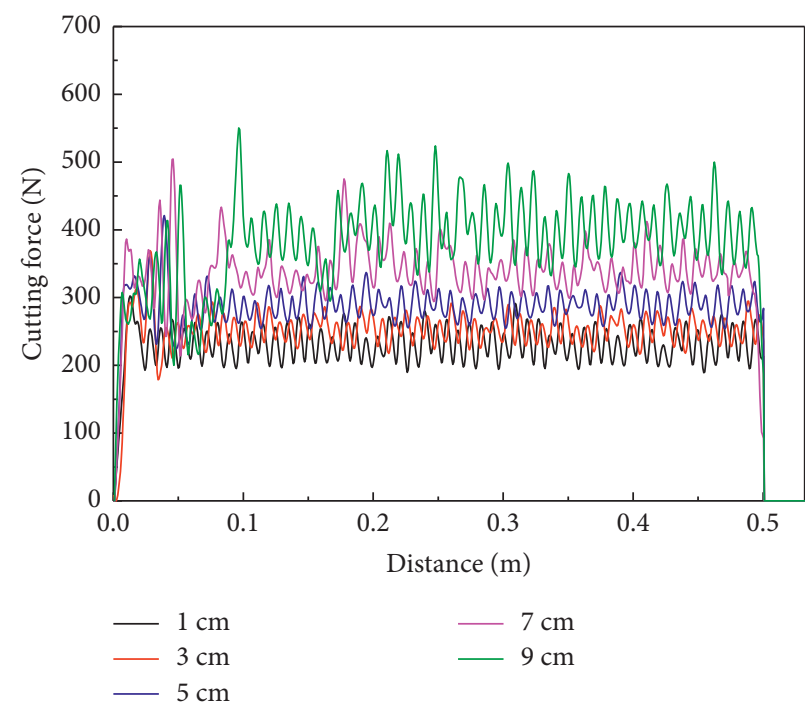

(a)

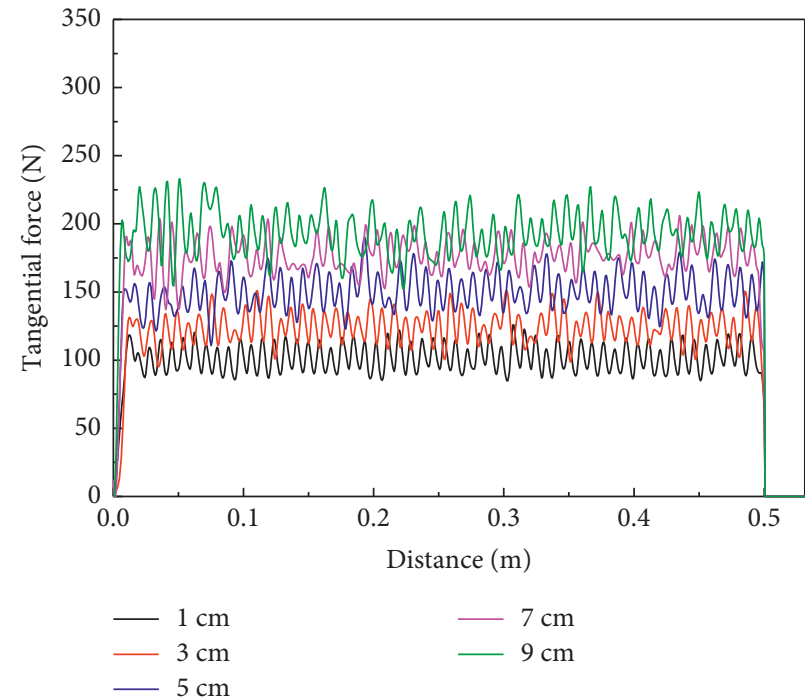

(c)

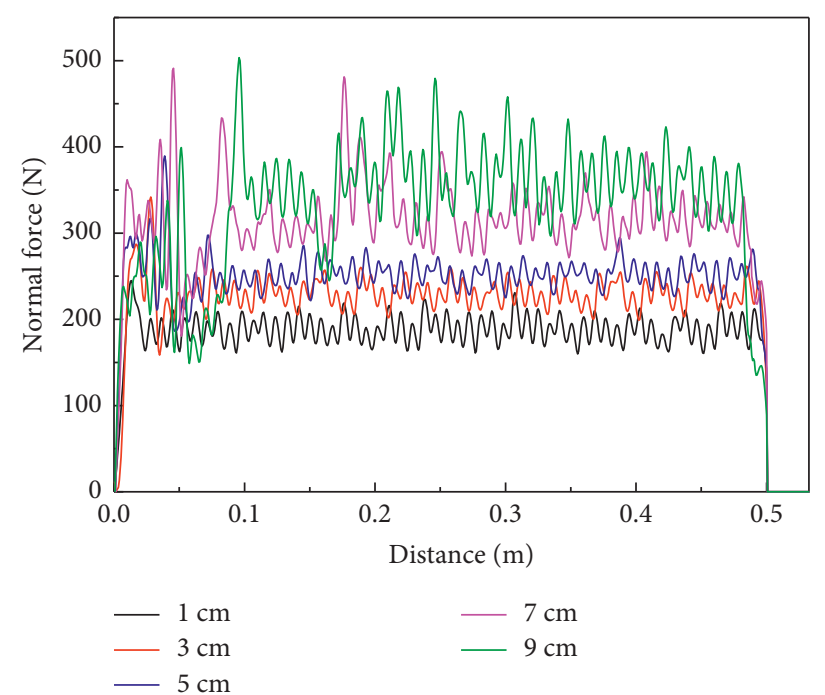

(b)

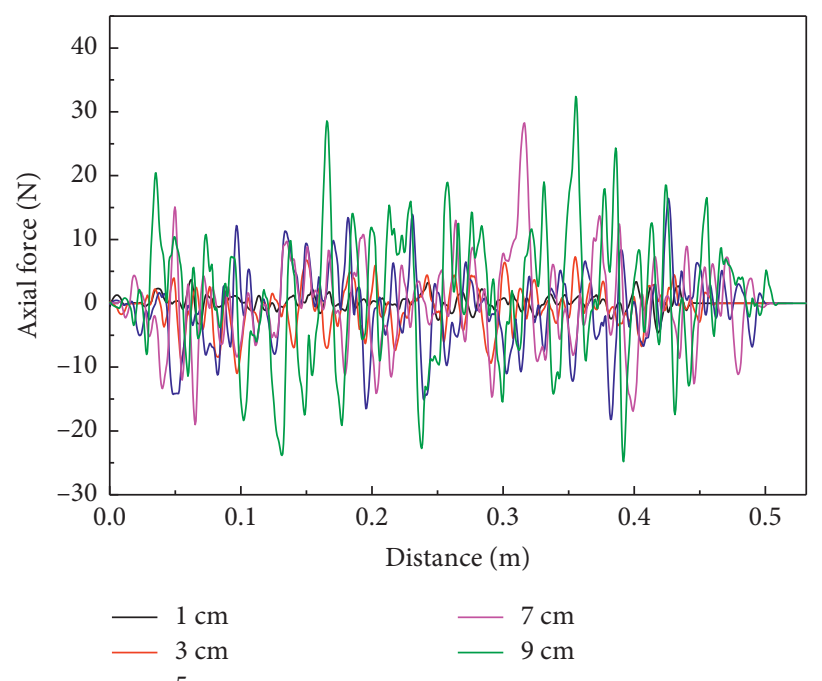

(d)

Figure 12: Variations in forces with distance for different cutting depths: (a) variation in the cutting force with distance for different cutting depths, (b) variation in the normal force with distance for different cutting depths, and (c) variation in the tangential force with distance for different cutting depths.

When the diamond sawblade cuts the rock with cutting depths of $1,3,5,7$, and $9 \mathrm{~cm}$, a rotation speed of $2000 \mathrm{r} / \mathrm{min}$ and a feed speed of $0.25 \mathrm{~m} / \mathrm{min}$, the cutting forces, normal forces, tangential forces, and axial forces on the diamond sawblades versus the cutting distance are shown in Figure 12.

It is obvious that the force increases with increasing cutting depth. The fluctuation amplitude of the cutting force curve had an increasing trend by comparing the cutting force with different cutting depths. The axial force fluctuation increased noticeably with increasing cutting depth, as seen from the axial force curves of the diamond sawblade. The depth of sawing by the sawblade increases the difficulty of discharging rock fragments and increases the interaction between the diamond sawblade and the rock, causing the fluctuations of the axial force to increase. The cutting depth of the diamond sawblade increased as the cutting force increased, and the fluctuation of the cutting force curve increased. The change trend of the normal force curve is similar to that of the cutting force curve. However, the fluctuation amplitude of the tangential force curve is basically the same, and the fluctuation range is not closely related to the changes in the cutting depth. It can be concluded that the cutting depth has a greater effect on the cutting force. The impact on the cutting force is mainly embodied in the normal force and the tangential force. The increasing normal force and tangential force causes the cutting force to increase. Furthermore, the fluctuation amplitude of the cutting force is mainly influenced by the amplitude of the normal force. 


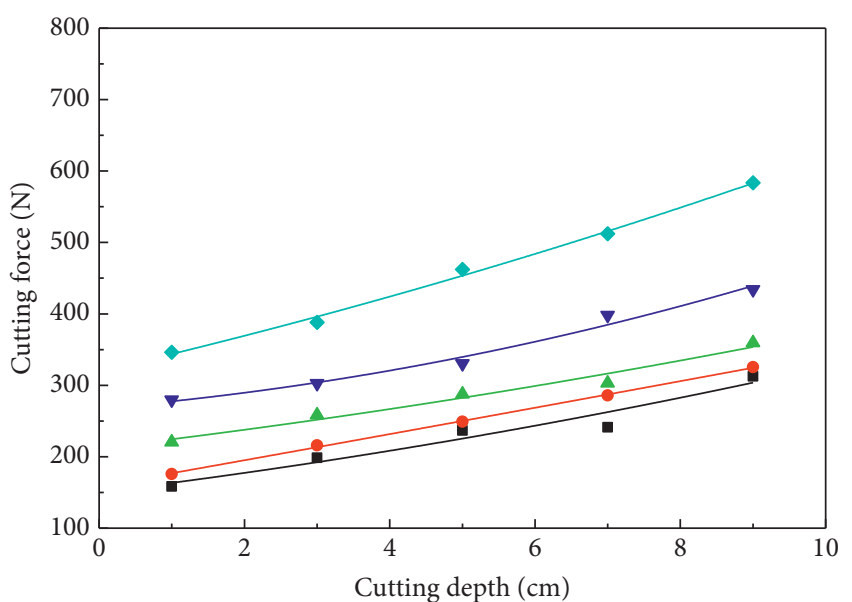

Cutting depth

- $0.200 \mathrm{~m} / \mathrm{s} y=0.512 x^{2}+12.4215 x+150.48588 \quad R^{2}=0.88902$

- $0.225 \mathrm{~m} / \mathrm{s} \quad y=0.04065 x^{2}+18.04957 x+150.48588 R^{2}=0.99985$

$\Delta 0.250 \mathrm{~m} / \mathrm{s} \quad y=0.41371 x^{2}+12.01362 x+212.07259 R^{2}=0.94427$

> $0.300 \mathrm{~m} / \mathrm{s} \quad y=1.17372 x^{2}+8.46906 x+267.96767 \quad R^{2}=0.96468$

- $0.350 \mathrm{~m} / \mathrm{s} \quad y=0.62235 x^{2}+23.67802 x+319.51257 R^{2}=0.99104$

(a)

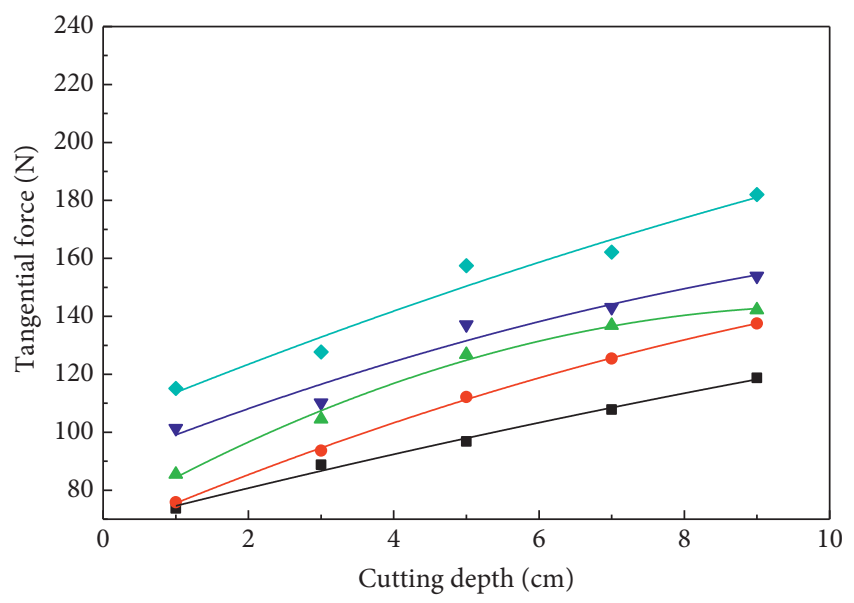

Cutting depth

- $0.200 \mathrm{~m} / \mathrm{s} \quad y=-0.09486 x^{2}+6.4064 x+68.27752 \quad R^{2}=0.98818$

- $0.225 \mathrm{~m} / \mathrm{s} \quad y=-0.2971 x^{2}+10.72517 x+65.09136 \quad R^{2}=0.99849$

$\Delta .250 \mathrm{~m} / \mathrm{s} \quad y=-0.70738 x^{2}+14.36252 x+70.71812 R^{2}=0.98773$

> $0.300 \mathrm{~m} / \mathrm{s} \quad y=-0.30483 x^{2}+9.94916 x+89.44798 \quad R^{2}=0.92176$

- $0.350 \mathrm{~m} / \mathrm{s} \quad y=-0.19075 x^{2}+10.32294 x+103.5661 R^{2}=0.93359$

(c)

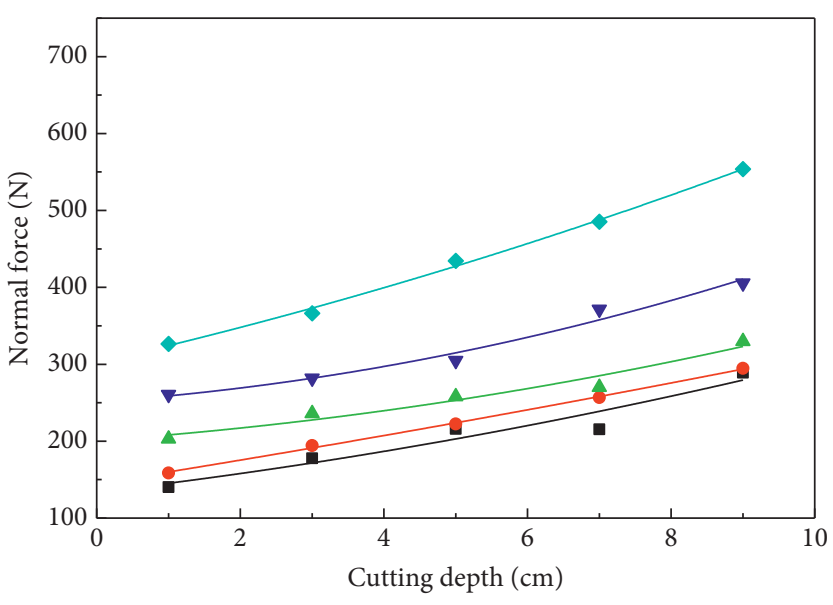

Cutting depth

- $0.200 \mathrm{~m} / \mathrm{s} \quad y=0.59123 x^{2}+10.8575 x+133.8396 R^{2}=0.85864$

- $0.225 \mathrm{~m} / \mathrm{s} \quad y=0.1882 x^{2}+14.8414 x+144.93629 R^{2}=0.99702$

$\Delta \quad 0.250 \mathrm{~m} / \mathrm{s} \quad y=0.7769 x^{2}+6.60473 x+200.78649 R^{2}=0.91081$

> $0.300 \mathrm{~m} / \mathrm{s} \quad y=1.2417 x^{2}+6.53949 x+251.10011 R^{2}=0.95797$

- $0.350 \mathrm{~m} / \mathrm{s} \quad y=0.7204 x^{2}+21.47051 x+302.1217 R^{2}=0.99383$

(b)

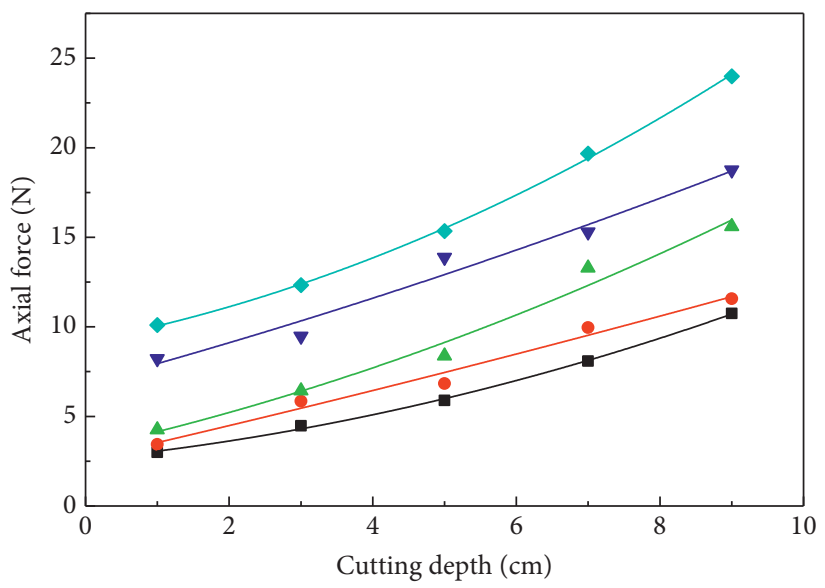

Cutting depth

- $0.200 \mathrm{~m} / \mathrm{s} \quad y=0.05596 x^{2}+0.39649 x+2.61051 \quad R^{2}=0.99741$

- $0.225 \mathrm{~m} / \mathrm{s} \quad y=0.00989 x^{2}+0.91956 x+2.60901 \quad R^{2}=0.96447$

$\Delta 0.250 \mathrm{~m} / \mathrm{s} \quad y=0.05781 x^{2}+0.89904 x+3.1894 \quad R^{2}=0.9631$

> $0.300 \mathrm{~m} / \mathrm{s} \quad y=0.02531 x^{2}+1.09111 x+6.83017 \quad R^{2}=0.94869$

- $0.350 \mathrm{~m} / \mathrm{s} \quad y=0.05596 x^{2}+0.39649 x+2.61051 \quad R^{2}=0.99741$

(d)

FIGURE 13: Relationship between the average force and the cutting depth with different feed speeds: (a) relationship between the average cutting force and cutting depth with different feed speeds, (b) relationship between the average normal force and cutting depth with different feed speeds, (c) relationship between the average tangential force and cutting depth with different feed speeds, and (d) relationship between the average axial force and cutting depth with different feed speeds.

The fitting curves between the cutting depth and the cutting force, normal force, tangential force, and axial force are shown in Figure 13. In the process of fixed deep cutting, the fitting functional expression between the cutting distance and the cutting force, normal force, tangential force, and axial force is $y=A x^{2}+B x+C$. The relationship expressions and correlation coefficients of the cutting depth and the average force are shown in Figure 13.
3.5. Influences of the Cutting Parameters on Rock Damage. In the dynamic simulation, the diamond sawblade cut rock with different rotation speeds, cutting depths, and feed speeds. The interaction force of the diamond sawblade and the rock has a certain influence on the hard rock on both sides of the saw seam. After the initial crack of the rock is compressed by the diamond sawblade, a certain amount of damage is produced by transient elastic compression and 


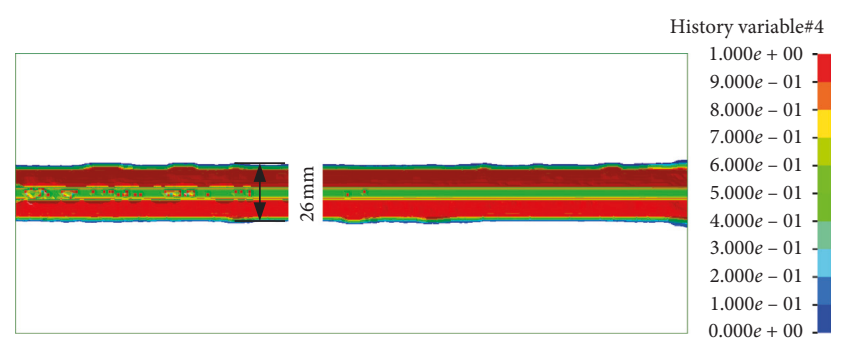

(a)

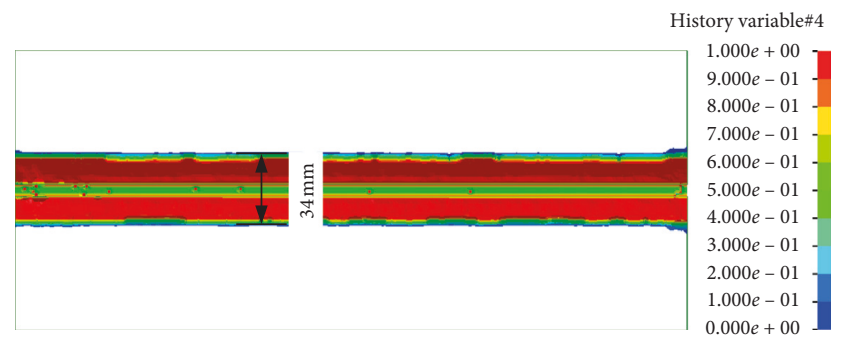

(c)

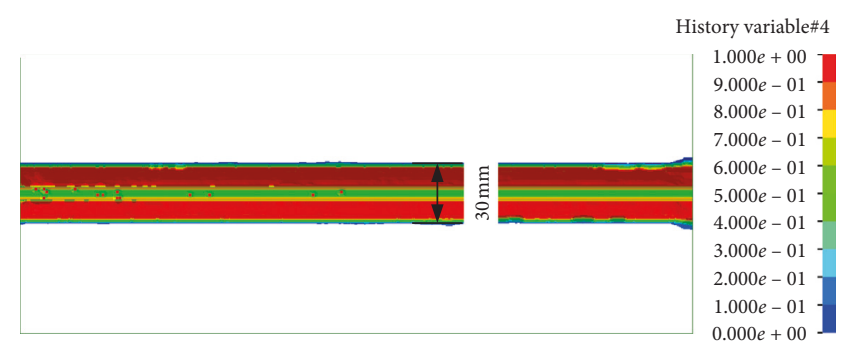

(b)

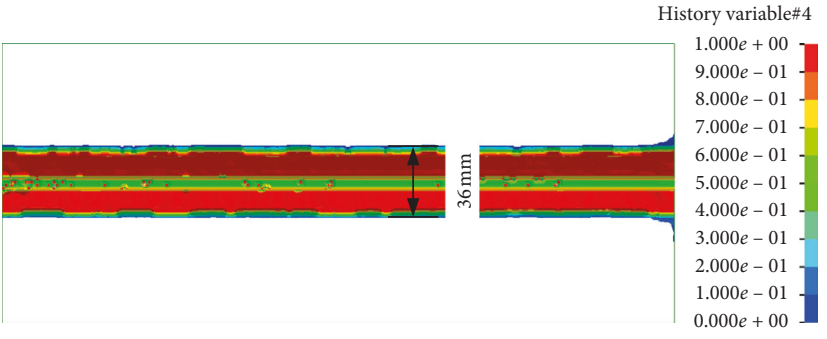

(d)

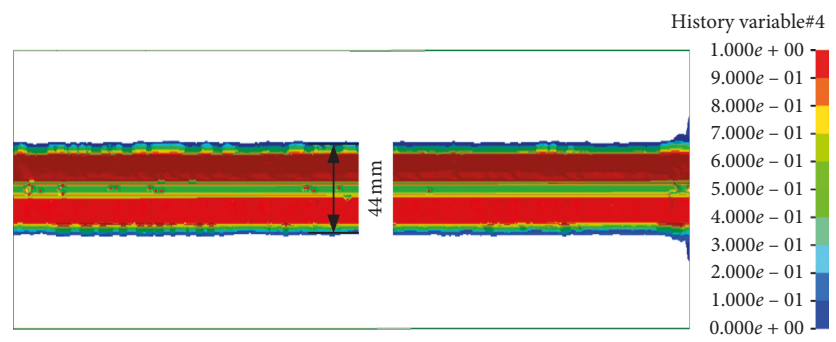

(e)

FiguRE 14: Damage nephogram for different feed speeds. (a) Feed speed $0.200 \mathrm{~m} / \mathrm{min}$. (b) Feed speed $0.225 \mathrm{~m} / \mathrm{min}$. (c) Feed speed $0.250 \mathrm{~m} / \mathrm{min}$. (d) Feed speed $0.300 \mathrm{~m} / \mathrm{min}$. (e) Feed speed $0.350 \mathrm{~m} / \mathrm{min}$.

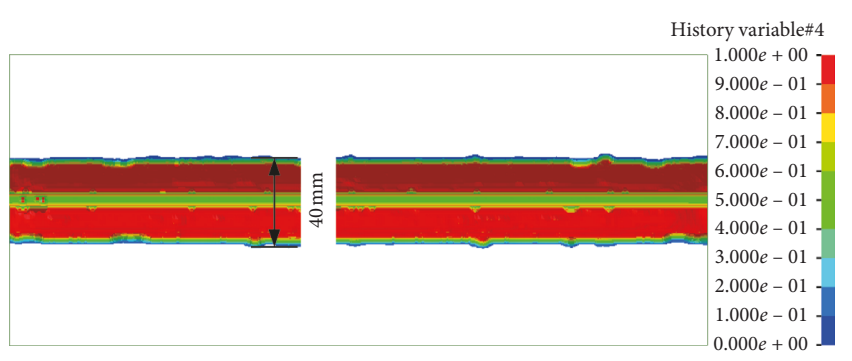

(a)

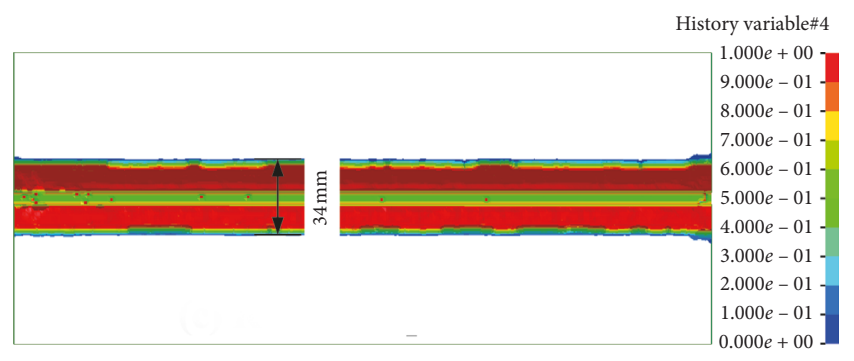

(c)

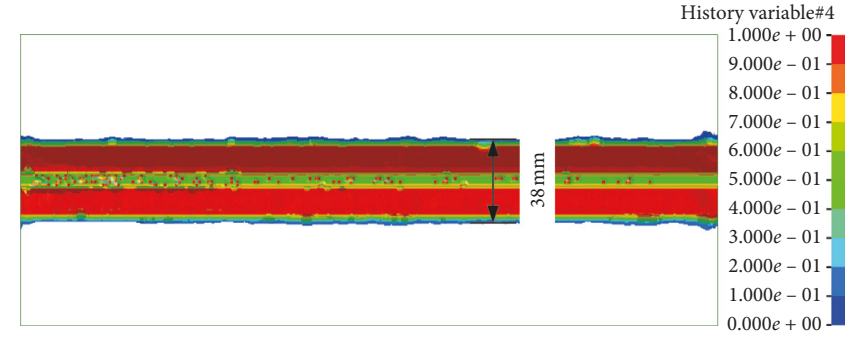

(b)

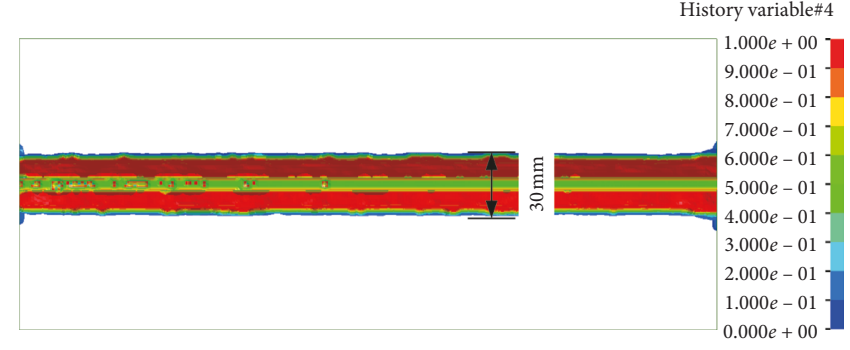

(d)

FIgURe 15: Continued. 


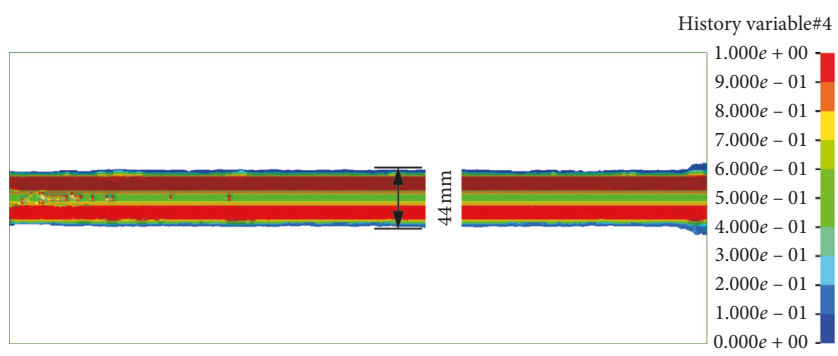

(e)

FIGURE 15: Damage nephograms for different rotation speeds. (a) Rotation speed $1000 \mathrm{r} / \mathrm{min}$. (b) Rotation speed $1500 \mathrm{r} / \mathrm{min}$. (c) Rotation speed $2000 \mathrm{r} / \mathrm{min}$. (d) Rotation speed $2500 \mathrm{r} / \mathrm{min}$. (e) Rotation speed $3500 \mathrm{r} / \mathrm{min}$.

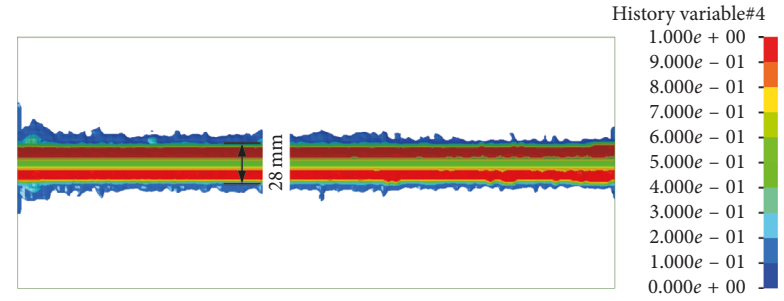

(a)

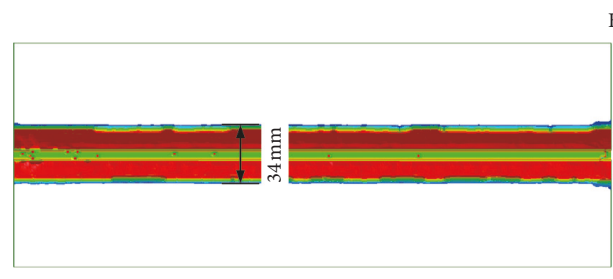

(c)

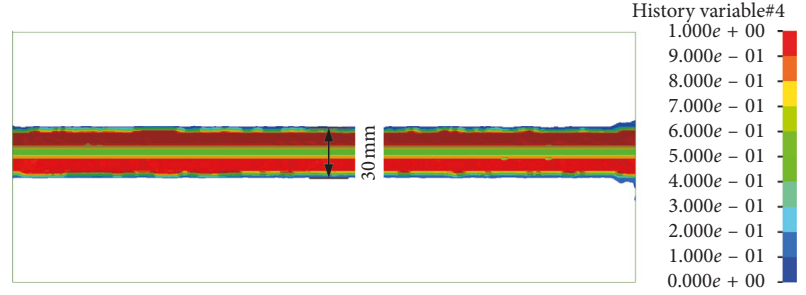

(b)

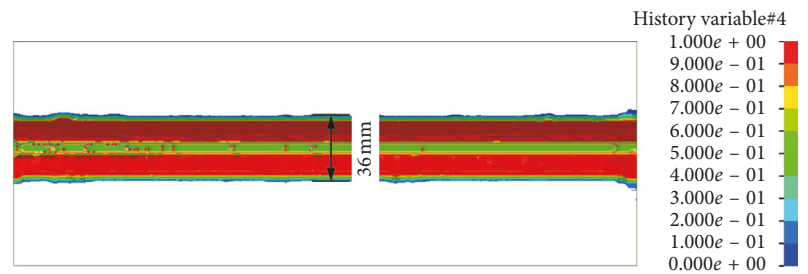

(d)

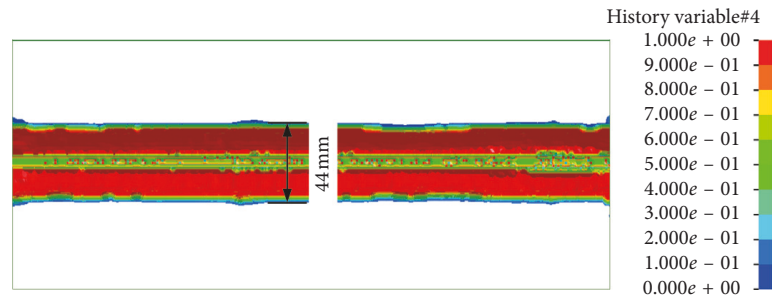

(e)

Figure 16: Damage nephograms for different cutting depths. (a) Cutting depth $1 \mathrm{~cm}$. (b) Cutting depth $3 \mathrm{~cm}$. (c) Cutting depth $5 \mathrm{~cm}$. (d) Cutting depth $7 \mathrm{~cm}$. (e) Cutting depth $9 \mathrm{~cm}$.

irreversible plastic deformation. The degree of damage to the rock is closely related to the stress of the rock, so different cutting parameters have a great impact on the degree of rock damage. It can be seen that with the increase in feed speed, the damage zone is increased, and the degree of damage degree is also increased, as shown in the cloud figure of different feeding speeds in Figure 14.

Rock was cut with the diamond sawblade with a feed speed of $0.25 \mathrm{~m} / \mathrm{min}$, a cutting depth of $5 \mathrm{~cm}$ and rotation speeds of $1000,1500,2000,2500$, and $3500 \mathrm{r} / \mathrm{min}$ to study the influence of the rotation speed on the rock damage. The damage zone of the hard rock and the degree of damage were smaller with increasing rotation speed, which is distributed with respect to the sawblade. Damage nephograms with different rotation speeds are presented in Figure 15.
Figure 16 shows damage nephograms of rock cutting with diamond sawblades at different cutting depths. As the cutting depth increases, the damage zone and the degree of damage increase. When the cutting depth is decreased, an uneven distribution of the damage cloud on both sides of the saw results from the cutting axial forces easily expanding outward.

3.6. Influences of the Cutting Parameters on Specific CuttingEnergy. The product of the average cutting force and cutting distance of a diamond sawblade is defined as the cutting energy consumption of a diamond sawblade, and the specific energy consumption is defined as the ratio of the cutting energy consumption and the volume of rock removed. In this paper, the relational expression was obtained 
TABle 2: Regression results to predict the diamond sawblade performance.

\begin{tabular}{|c|c|c|c|c|c|}
\hline Variables & Cutting parameter & Regression equation & Correlation coefficient & $F$-value & $P$ value \\
\hline SE-FS & Cutting depth of $1 \mathrm{~cm}$ & $y=11.42824 x^{2}-2.02953 x+0.61463$ & 0.98417 & 125.30464 & $5.7 \mathrm{e}^{-4}$ \\
\hline SE-FS & Cutting depth of $3 \mathrm{~cm}$ & $y=11.42824 x^{2}-4.43866 x+0.93703$ & 0.99322 & 293.83917 & $1.8 \mathrm{e}^{-4}$ \\
\hline SE-FS & Cutting depth of $5 \mathrm{~cm}$ & $y=10.60784 x^{2}-4.34054 x+0.38059$ & 0.92829 & 26.88862 & 0.00134 \\
\hline SE-FS & Cutting depth of $7 \mathrm{~cm}$ & $y=5.95759 x^{2}-1.98856 x+0.585675$ & 0.97888 & 93.69311 & $2.7 \mathrm{e}^{-4}$ \\
\hline SE-FS & Cutting depth of $9 \mathrm{~cm}$ & $y=8.99425 x^{2}-3.48346 x+0.70192$ & 0.99464 & 372.24357 & $9.1 \mathrm{e}^{-5}$ \\
\hline SE-RS & Cutting depth of $1 \mathrm{~cm}$ & $y=-1.11000 e^{-3} x+0.82366$ & 0.92196 & 48.25547 & 0.00282 \\
\hline SE-RS & Cutting depth of $3 \mathrm{~cm}$ & $y=-9.76846 e^{-4} x+0.74836$ & 0.92214 & 48.37552 & 0.00219 \\
\hline SE-RS & Cutting depth of $5 \mathrm{~cm}$ & $y=-9.50260 e^{-4} x+0.71639$ & 0.96328 & 105.91909 & $9.5 e^{-4}$ \\
\hline SE-RS & Cutting depth of $7 \mathrm{~cm}$ & $y=-9.35802 e^{-4} x+0.65677$ & 0.87846 & 29.91088 & 0.00325 \\
\hline SE-RS & Cutting depth of $9 \mathrm{~cm}$ & $y=-8.95074 e^{-4} x+0.58997$ & 0.92743 & 52.12186 & 0.00171 \\
\hline
\end{tabular}

$\mathrm{SE}=$ specific energy; $\mathrm{FS}=$ feed speed; $\mathrm{RS}=$ rotation speed.
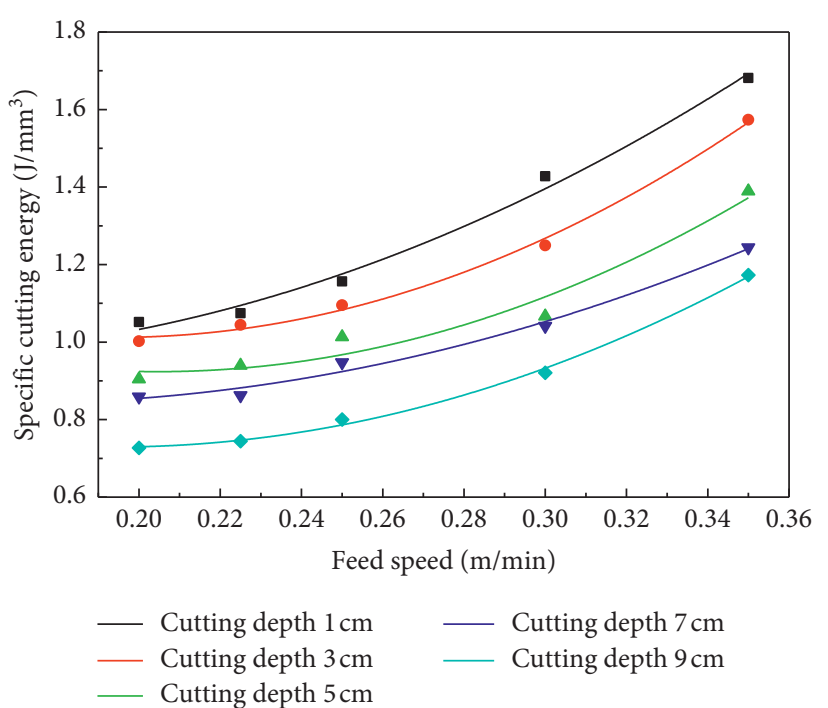

FIGURE 17: Relationship between the cutting energy consumption and feed speed at different cutting depths.

by fitting the specific energy consumption and the feed speed and the rotation speed, as shown in Table 2. The influence of the diamond sawblade feed speed and rotation speed on the specific energy consumption is as follows: with increasing feed speed in a quadratic relationship, the diamond sawblade rotation speed linearly decreases, and the specific energy consumption decreases with the increase in cutting depth, as shown in the curves in Figures 17 and 18.

Not only do the feed speed and the rotation speed affect the cutting energy consumption significantly, but the cutting depth also has a large effect on the cutting energy consumption. Multiple linear regression analysis was conducted to determine the effects of multiple variables on the dependent variables simultaneously. For cutting rock with a diamond sawblade, the specific cutting energy consumption is set as the dependent variable, and the feed speed, rotation speed, and cutting depth are independent variables. Multivariate linear analysis was used to identify the relationship among the specific cutting energy and the 3 independent variables.

For convenience of analysis, the specific cutting energy is defined as $Y$, and the independent variables, namely, the feed speed, rotation speed and the cutting depth, are defined as $X 1$, $X 2$, and $X 3$, respectively. The expression of the multivariable

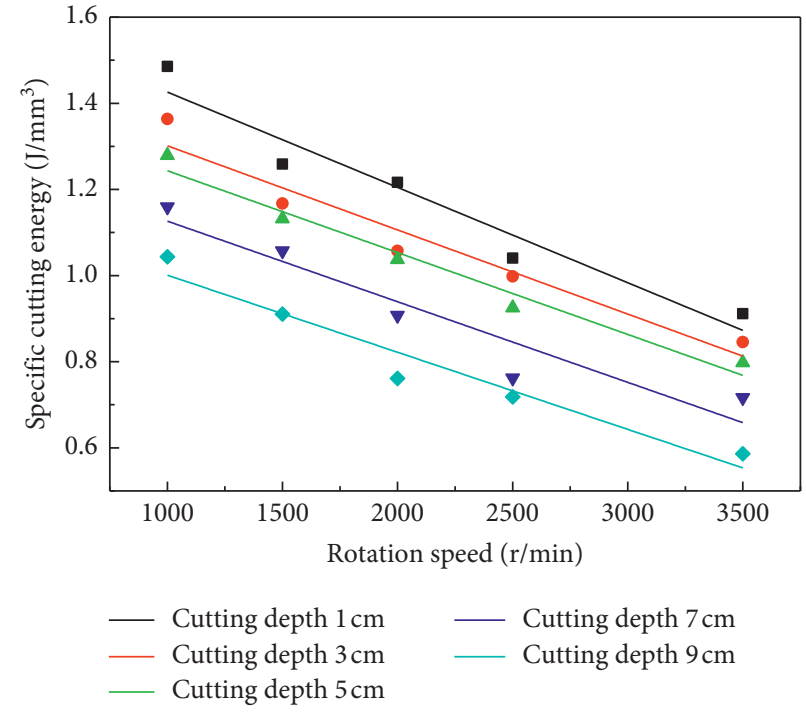

FIgURE 18: Relationship between the cutting energy consumption and rotation speed at different cutting depths.

linear function is $Y=\varphi+A X 1-B X 2-C X 3$, where $\varphi$ is the intercept and $A, B$, and $C$ are the coefficients of the feed speed, rotation speed, and cutting depth, respectively. The multiple linear function fits the specific cutting energy consumption with respect to the feed speed, the rotation speed, and the cutting depth, and the expression was obtained as follows: $Y=0.41+1.679 X 1-0.097 X 2-0.24 X 3$.

\section{Conclusions}

The finite element software LS-DYNA was used to study the process of diamond sawblades cutting rock. The rock in the numerical simulation model determined the material model, which included the damage failure criterion, to research the force and rock damage in the process of cutting rock with a diamond sawblade. The influences of feed speed, rotation speed, and cutting depth on forces, rock damage, and specific cutting energy were studied.

(1) The force of the diamond sawblade increases with the increase in feed speed and cutting depth and 
decreases with the increase in rotation speed during the cutting of hard rock with a diamond sawblade. The fluctuation of the forces increases with increasing feed speed and cutting depth and decreases with increasing rotation speed.

(2) The degree of rock damage increases with increasing cutting depth and feed speed of the diamond sawblade. The increase in rotation speed of the diamond sawblade causes the damage zone of the rock to decrease.

(3) The specific cutting energy consumption increases to the second power with the feed speed, and the rock specific cutting energy consumption decreases linearly with the rotation speed. However, the cutting energy consumption decreases to a certain extent with increasing cutting depth of the diamond sawblade.

\section{Data Availability}

The data used to support the findings of this study are included within the article.

\section{Conflicts of Interest}

The authors declare that there are no conflicts of interest regarding the publication of this paper.

\section{Acknowledgments}

This work was supported by projects of the National Natural Science Foundation of China (Grant no. 51674155), the Natural Science Foundation of Shandong Province (Grant nos. ZR2016EEM02 and ZR2017MEE034), and Special Funds for Cultivation of Taishan Scholars.

\section{References}

[1] M. Yurdakul and H. Akdas, "Prediction of specific cutting energy for large diameter circular saws during natural stone cutting," International Journal of Rock Mechanics and Mining Sciences, vol. 53, pp. 38-44, 2012.

[2] M. Yurdakul, "Effect of cutting parameters on consumed power in industrial granite cutting processes performed with the multi-disc block cutter," International Journal of Rock Mechanics and Mining Sciences, vol. 76, pp. 104-111, 2015.

[3] J. Konstanty, "Theoretical analysis of stone sawing with diamonds," Journal of Materials Processing Technology, vol. 123, no. 1, pp. 146-154, 2002.

[4] Y. Q. Yu, Y. Li, and X. P. Xu, "An experimental study of specific energy in grinding granite," Materials Science Forum, vol. 471-472, pp. 625-629, 2004.

[5] Q. Sun, J. Zhang, Z. Wang, H. Zhang, and J. Fang, "Segment wear characteristics of diamond frame saw when cutting different granite types," Diamond and Related Materials, vol. 68, pp. 143-151, 2016.

[6] I. Karakurt, G. Aydin, and K. Aydiner, "Experimental and statistical analysis of cutting force acting on diamond sawblade in sawing of granitic rocks," Proceedings of the Institution of Mechanical Engineers, Part B: Journal of Engineering Manufacture, vol. 227, no. 2, pp. 286-300, 2013.
[7] N. Sengun and R. Altindag, "Prediction of specific energy of carbonate rock in industrial stones cutting process," Arabian Journal of Geosciences, vol. 6, no. 4, pp. 1183-1190, 2013.

[8] L. M. Hellström, S.-O. Biller, S. Edvardsson, and P. A. Gradin, "A theoretical and experimental study of the circular sawing process," Holzforschung, vol. 68, no. 3, 2014.

[9] N. E. Yasitli, F. Bayram, B. Unver, and Y. Ozcelik, "Determination of reactional cutting forces on a circular sawblade machine by using experimental studies and numerical modelling," Proceedings of the Institution of Mechanical Engineers, Part C: Journal of Mechanical Engineering Science, vol. 226, no. 3, pp. 775-784, 2012.

[10] J. Asche, H. K. Tönshoff, and T. Friemuth, "Cutting Principles, wear and applications of diamond tools in the stone and civil engineering industry," in Proceedings of the Diamond Tools Conference, pp. 151-157, University of Hanover, Hanover, Germany, December 1999.

[11] S. Turchetta, "Cutting force in stone machining by diamond disk," Advances in Materials Science and Engineering, vol. 2010, Article ID 631437, 6 pages, 2010.

[12] X. Xu, Y. Li, and S. Malkin, "Forces and energy in circular sawing and grinding of granite," Journal of Manufacturing Science and Engineering, vol. 123, no. 1, pp. 13-22, 2000.

[13] X. Xu, Y. Li, and Y. Yu, "Force ratio in the circular sawing of granites with a diamond segmented blade," Journal of Materials Processing Technology, vol. 139, no. 1-3, pp. 281-285, 2003.

[14] S. Turchetta, "Cutting force and diamond tool wear in stone machining," The International Journal of Advanced Manufacturing Technology, vol. 61, no. 5-8, pp. 441-448, 2012.

[15] Q. Zeng, Z. Wang, L. Wan, X. Zhang, and Z. Lu, "Study on the damage of coal and rock with diamond saw blade cutting based on LS-DYNA," International Journal of Computational Materials Science and Engineering, vol. 6, no. 4, Article ID 1750026, 2018.

[16] LS-DYNA, Keyword User's Manual, Version 970, Livermore Software Tech-nology Corporation, Livermore, California, April 2003.

[17] Z. Lu, L. Wan, Q. Zeng, X. Zhang, and K. Gao, "Numerical simulation of fragment separation during rock cutting using a 3D dynamic finite element analysis code," Advances in Materials Science and Engineering, vol. 2017, Article ID 3024918, 17 pages, 2017.

[18] I. Evans, "A theory of the cutting force for point-attack picks," International Journal of Mining Engineering, vol. 2, no. 1, pp. 63-71, 1984.

[19] I. Evans, "Optimum line spacing for cutting picks," Mining Engineer, vol. 141, pp. 433-434, 1982.

[20] L. Tang, "Study on the rock statistical damage constitutive model," International Journal of Mechanics Research, vol. 3, no. 3, pp. 23-32, 2014.

[21] Y. Furukawa, S. Ohishi, and S. Shiozaki, "Selection of creep feed grinding conditions in view of workpiece burning," CIRP Annals, vol. 28, no. 1, pp. 213-218, 1979.

[22] C. Guo, N. Krishnan, and S. Malkin, "Matching forces and power in creep-feed grinding," in Proceedings of the 5th International Grinding Conference, SME Paper MR93-363, Cincinaati, OH, October 1993. 


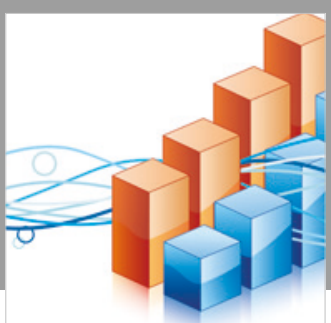

Advances in

Operations Research

\section{-n-m}
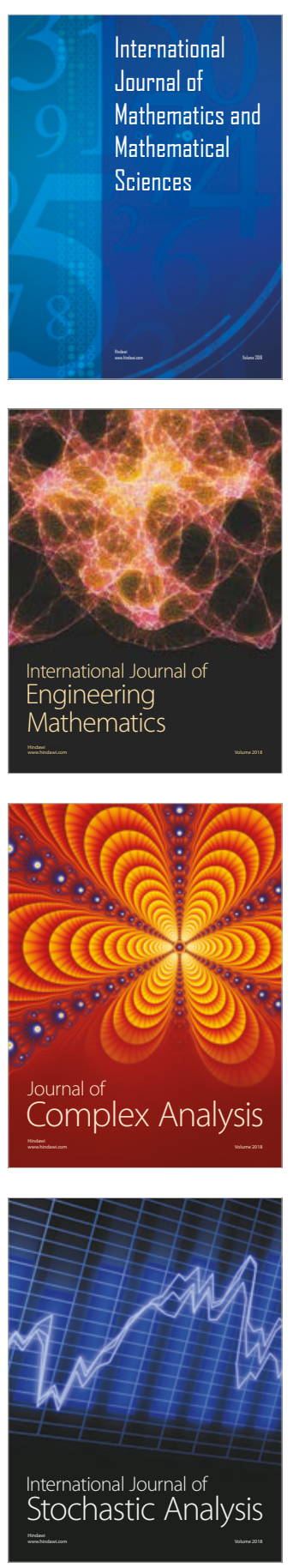
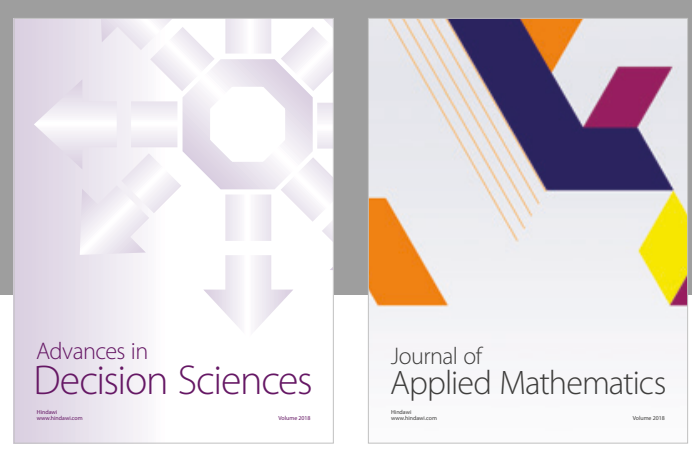

Journal of

Applied Mathematics
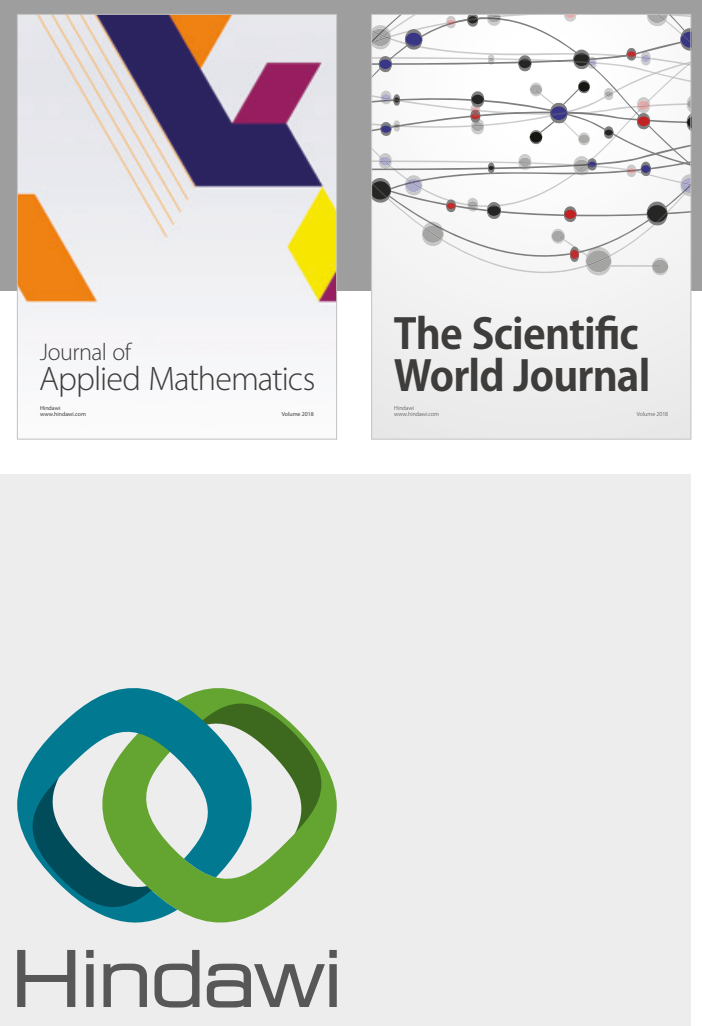

Submit your manuscripts at

www.hindawi.com

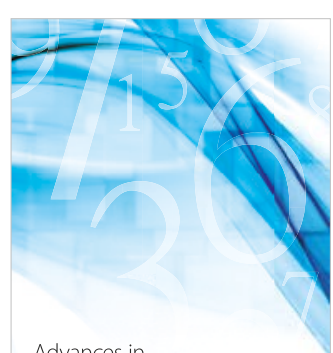

Advances in
Numerical Analysis
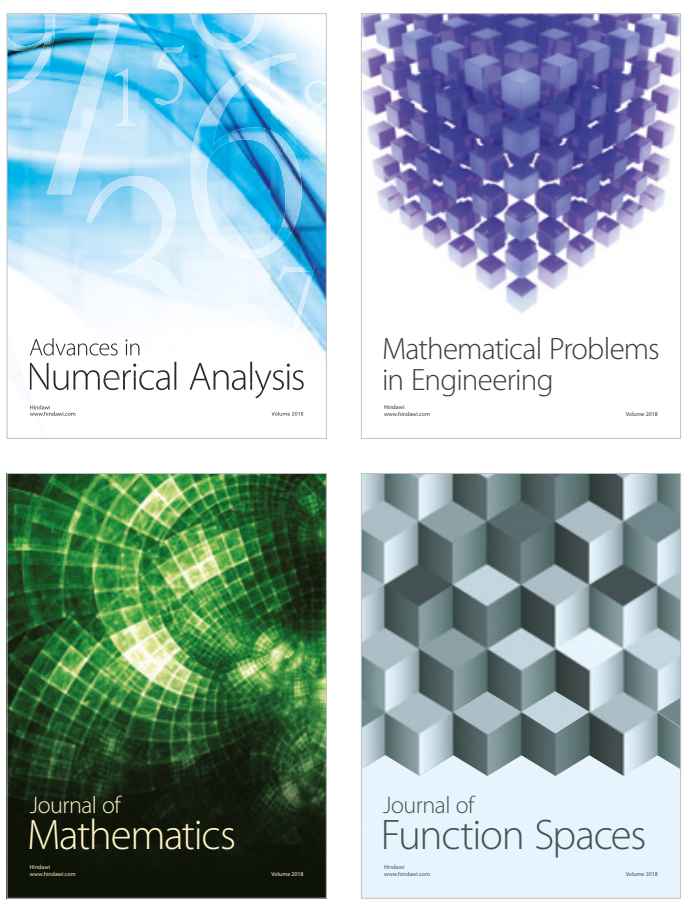

Mathematical Problems in Engineering

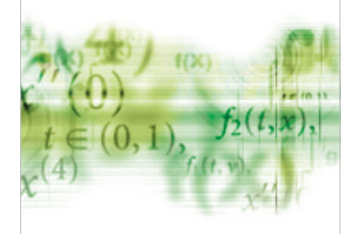

International Journal of

Differential Equations

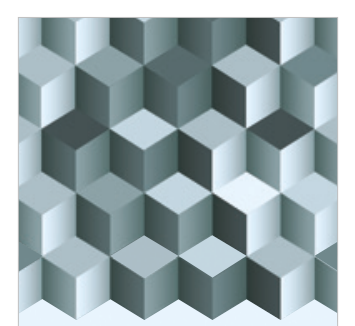

Journal of

Function Spaces

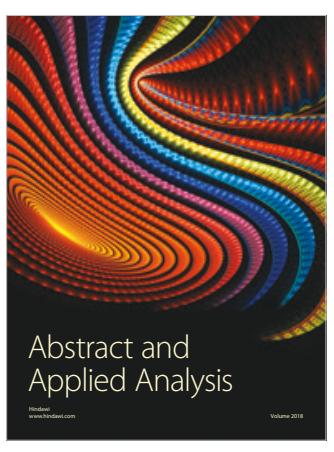

The Scientific

World Journal

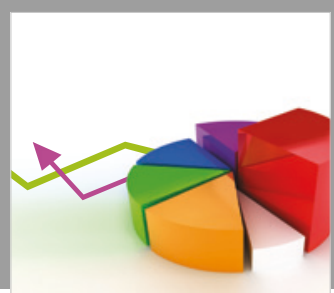

Journal of

Probability and Statistics
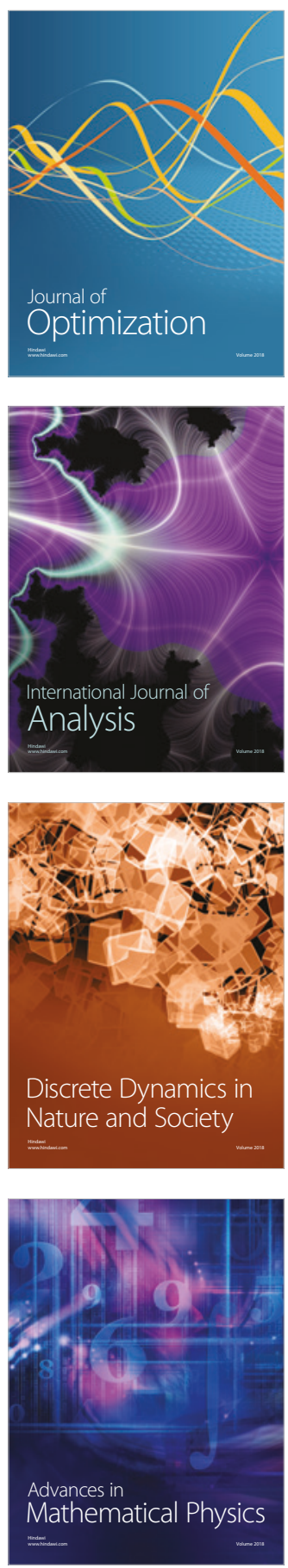